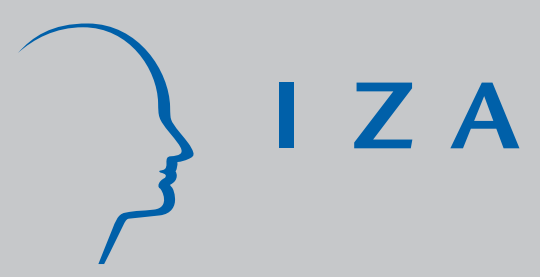

IZADP No. 3633

The Effect of Extending the Duration of Eligibility in an Italian Labour Market Programme for Dismissed Workers

Enrico Rettore Adriano Paggiaro Ugo Trivellato

August 2008 


\title{
The Effect of Extending the Duration of Eligibility in an Italian Labour Market Programme for Dismissed Workers
}

\author{
Enrico Rettore \\ University of Padova
}

Adriano Paggiaro

University of Padova

Ugo Trivellato

University of Padova,

CESifo and IZA

\section{Discussion Paper No. 3633 \\ August 2008}

IZA
P.O. Box 7240
53072 Bonn
Germany

Phone: +49-228-3894-0

Fax: +49-228-3894-180

E-mail: iza@iza.org

\begin{abstract}
Any opinions expressed here are those of the author(s) and not those of IZA. Research published in this series may include views on policy, but the institute itself takes no institutional policy positions.

The Institute for the Study of Labor (IZA) in Bonn is a local and virtual international research center and a place of communication between science, politics and business. IZA is an independent nonprofit organization supported by Deutsche Post World Net. The center is associated with the University of Bonn and offers a stimulating research environment through its international network, workshops and conferences, data service, project support, research visits and doctoral program. IZA engages in (i) original and internationally competitive research in all fields of labor economics, (ii) development of policy concepts, and (iii) dissemination of research results and concepts to the interested public.
\end{abstract}

IZA Discussion Papers often represent preliminary work and are circulated to encourage discussion. Citation of such a paper should account for its provisional character. A revised version may be available directly from the author. 


\title{
ABSTRACT
}

\section{The Effect of Extending the Duration of Eligibility in an Italian Labour Market Programme for Dismissed Workers}

\begin{abstract}
Liste di mobilità (LM) is an Italian labour market programme targeted to dismissed workers. It combines a 'passive' component granting monetary benefits to employees dismissed by firms larger than 15 employees, and an 'active' component providing an employment subsidy to any firm hiring workers from the LM. Eligibility duration varies with the worker's age at dismissal. Using a new linked administrative panel data set for an Italian region, we exploit the variability of these provisions to evaluate the impact of extending the duration of eligibility on re-employment probabilities and wages over the 36 months subsequent to enrolment in the programme. The average treatment effect is identified via a Regression Discontinuity Design. We validate the design by a set of overidentification tests. For most of the subgroups we analyse, we find that a longer eligibility period has no impact on re-employment rates. A negative impact emerges for women entitled to monetary benefits at the end of the second year of eligibility, but it disappears one year later. A major negative impact emerges for workers aged 50 or more granted the monetary benefits; it is most likely due to the fact that they can use the LM as a bridge to retirement.
\end{abstract}

JEL Classification: $\quad \mathrm{C} 31, \mathrm{~J} 38, \mathrm{~J} 65, \mathrm{~J} 68$

Keywords: $\quad$ active labour market policies, regression discontinuity design

Corresponding author:

Ugo Trivellato

Faculty of Statistical Science

University of Padova

Via Cesare Battisti 241

35121 Padova

Italy

E-mail: trivell@stat.unipd.it

\footnotetext{
* Research for this paper was supported by grants 2003139334 and 2005131989 from the Italian Ministry of Education, University and Research, for the years 2004-05 and 2006-07, under the PRIN Programme. Microdata for this study were made available by Veneto Lavoro under a confidentiality agreement. (They might be obtained from Veneto Lavoro upon presentation of a research project and underwriting of a confidentiality agreement.) We are indebted to Bruno Anastasia, Maurizio Gambuzza and Maurizio Rasera for their invaluable expertise with the Netlabor archive. Previous versions ware presented at the Labor Economics Workshop Engelberg 2008, University of Zurich, at Seminars at the Universities of Geneva and Trento, and at the CESifo Area Conference on Employment and Social Protection, Ludwig-Maximilian Universitat, Munich, 23-24 May 2008. The usual disclaimer applies.
} 


\section{Introduction}

Liste di mobilità (LM) ${ }^{1}$ is an Italian labour market programme introduced in the early 1990s to handle redundancies in the labour market. The design of the programme is quite complex because of two reasons: first, it includes both a 'passive' and an 'active' component; second, it differentiates eligibility duration and benefits according to the age of the worker at dismissal and the size of the dismissing firm.

The passive component grants monetary benefits with a high replacement rate, but only to workers who have been dismissed by firms larger than 15 employees. The active component provides any firm hiring dismissed workers from the LM - either on a permanent or on a temporary contract - with an employment subsidy, consisting of a substantial reduction in social security contributions (SSCs) for that worker, for up to two years. In addition, firms hiring with a permanent contract any worker eligible for monetary benefits receive up to $50 \%$ of the residual benefit the worker would have received had s/he remained unemployed. The latter feature is close to the benefit transfer scheme proposed by Snower (1994).

The worker stays in the LM programme until s/he is hired on a permanent contract or until the end of the eligibility period, whichever comes first. Crucial to our analysis, the length of the eligibility period for both the passive and active components depends on the age of the worker at the time of dismissal: it is one year for workers younger than 40; it doubles to two years for those 40 to 49 years old; for workers older than 49 the eligibility status extends to three years, and even longer for workers entitled to monetary benefits when they are getting close to being eligible for retirement benefits - the latter is the so-called mobilità lunga ("long mobility"), designed to bridge unemployment and early retirement. Besides, during the time they are enrolled in the ML, workers are allowed to engage in temporary employment while maintaining their LM status (for details, see Section 2.2).

The aim of the programme is to bring dismissed workers back to work while providing them with an income maintenance. The rationale for extending eligibility from one to two to three years as a function of the worker age rests on the claim that ceteris paribus older workers are less attractive to employers, and thus face more difficulties in finding a new job once permanently separated from their previous one. The empirical basis upon which this claim rests is not clear, though. Besides, for workers in their fifties entitled to monetary benefits the provisions for "long mobility" alter substantially the rationale of the programme, with the income maintenance aim taking a dominant role. Thus a better understanding of the relationship between age and the extended eligibility for the LM programme would be useful for a possible redesign of the programme itself.

The identification of the impact of the whole programme is precluded by the lack of a sensible comparison group made up of ineligible workers suitably approximating the counterfactual for workers eligible to the LM. Only the differential impact of alternative packages of benefits is in principle identifiable. The research question we address in this paper regards the effect of extending the eligibility period from one to two years (workers aged less than 40 and in their forties, respectively) and from two to three years (workers in their forties and aged 50 or more, respectively) on the probability of being employed and on wages in each of the 36 months subsequent to enrolment in LM. The challenge we face is clear: how to separate the effects of extended duration of eligibility from the age effect, given that age is the only variable relevant for the duration of eligibility.

\footnotetext{
${ }^{1}$ Literally "Mobility Lists" where eligible workers are registered.
} 
The paper proceeds as follows. Section 2 illustrates some additional features of the programme useful to clarify the evaluation question we address, and presents a stylized example which illustrates how firms gain by hiring from the LM. Section 3 summarises evidence from previous studies. Section 4 briefly discusses the likely effect of the policy mix associated with an extended eligibility period. Section 5 expounds the strategy to identify the differential impact of the benefits, based on Regression Discontinuity Design (RDD). Section 6 describes our linked administrative panel data set - and its potentials - and presents the main empirical results. Section 7 concludes.

\section{The programme Liste di mobilità}

\subsection{The institutional context: a brief outline}

Italy is among the countries where workers are more protected on the job, by employment protection regulations and a generous pension system, than in the market, by passive and active labour market policies (see Esping-Andersen, 1990, for a broad review, and OECD, 2004, Ch. 2, for comparative evidence on the role of employment protection regulation).

The protection of workers against unjustified dismissals - i.e. dismissals due to reasons other than "just cause" or "serious economic reasons" - is fairly high (see Ichino, 2004, for an insightful scrutiny). For comparative purposes - across countries and/or over time, a convenient overall measure of workers' protection is the OECD's Employment Protection Legislation (EPL) indicator. The summary indicator of EPL strictness by the end of the 1990s is 3.1 for Italy: much higher than USA (0.7), UK (1.0) and Denmark (1.8), but close to - just slightly higher than - Spain, France, Germany, Norway and Sweden ${ }^{2}$.

An additional point is worth emphasising for Italy. The firm size threshold of 15 employees has broad repercussions on the Italian unemployment insurance and employment protection systems. At this threshold there are several discontinuities in labour market regulations (among which the one just mentioned for the LM programme), the main being precisely the provisions against unjust dismissals of permanent employees, who benefit of much stronger protection if employed by larger firms (Schivardi and Torrini, 2004).

As for welfare measures, the picture is basically opposite. The OECD summary measure of net (i.e. after tax) replacement rates - which, in addition to unemployment insurance (UI), includes welfare benefits such as social assistance, lone-parent benefits, etc. - is around $45 \%$ for Italy, well below the 65\% OECD average (Martin and Grubb, 2001, Figure 3). Specifically, UI to any worker not eligible for the LM is definitely low. Over the period covered by our analyses, recipients of the standard UI are unemployed individuals who meet the requirement of having been previously employed at least 52 weeks out of the last 104 ones and at least one further week previously, with SSCs: the replacement rate of standard UI is $30 \%$, and lasts a maximum of six months ${ }^{3}$. Unemployed individuals looking for their first job - or with previous work experience but not

\footnotetext{
${ }^{2}$ OECD (2004), p. 105. Data for 2003, at p. 70, document a neat decline of EPL strictness in Italy, both in absolute and comparative terms. Previous estimates of such indicator suffered from an upward bias for Italy: see Del Conte, Devillanova and Morelli (2004) and OECD (2004), p. 108.

${ }^{3}$ In addition to the case of workers enrolled in the LM, an exception is offered by the Cassa Integrazione Guadagni Straordinaria (CIGS). Workers employed by large firms that experienced plant closures or collective redundancies due to structural changes are usually granted access to CIGS: a special fund that pays them substantial benefits while they retain a formal link to their employer - in principle they are workers temporarily laid off. Workers might stay in this fund for an unlimited number of years, depending on agreements between trade unions and employers' organizations and on a final decision by Government - indeed, the fund is almost entirely supported by the taxpayer.
} 
meeting the eligibility requirement above - draw no unemployment benefits at all.

More generally, in Italy the share of public spending on active and passive labour market measures is comparatively modest (Martin and Grubb, 2001, Table 1, and OECD, 2005, Statistical Appendix, Table H). The bulk of Italian active labour market policies is made-up of traditional measures, such as training (especially financial support to apprenticeship) and recruitment incentives, with almost no room for new programmes such as welfare to work policies and the socalled "mutual obligations" programmes, which combine activation strategies with increased monitoring of job-seekers and enforcement of work tests (OECD, 2005, Ch. 3).

\subsection{Basic provisions of the LM programme}

\subsubsection{Conditions for enrolment and eligibility duration}

The LM programme is mainly regulated by laws No. 233/1991 and 236/1993 ${ }^{4}$. Firms with more than 15 employees $^{5}$ (we will refer to them as 'large' firms), may collectively ${ }^{6}$ dismiss $^{\text {ins }}$ redundant workers - because of plant closure or restructuring - and automatically enrol them in a special register maintained by a regional authority. Workers dismissed by firms up to 15 employees (we will refer to them as 'small' firms) may also enrol in the LM on a voluntary basis. Informed evidence indicates that most eligible workers dismissed by small firms do register in the Lists. To be eligible for the LM the worker must have been at least one year on a permanent contract with the dismissing firm. The basic features of the programme are summarised in Table 1.

\subsubsection{The passive component (only for workers dismissed by large firms)}

As for the passive component of the programme, workers dismissed by large firms receive the so-called indennità di mobilità, a monetary benefit to replace their last gross wage at a rate as large as $80 \%$ during the first year in the LM, dropping to $64 \%-80 \%$ of the first-year benefit during the second and third year (for workers eligible for more than one year), with a ceiling that varies over time.

Furthermore, a special provision holds for workers older than 49 dismissed by large firms and meeting some additional conditions with respect to retirement rules. They are entitled to remain in the LM, drawing the monetary benefit, up to their retirement age - as anticipated, this is the socalled "long mobility". The crucial additional eligibility condition is to have 28 years of SSCs, including years spent in the LM. Thus, a 50-year old worker with an uninterrupted occupational history should have begun working no late than his/her 25 .

By contrast, enrolled workers dismissed by small firms receive just the standard UI (30\% of their last wage up to six months), provided that they meet the requirements for it (see Section 2.1 above). As our empirical analyses will focus on workers around the 40- and 50-year thresholds, these requirements are generally met.

Workers in the LM should in principle fulfil some obligations with respect to training and job offers. An LM worker who refuses an appropriate job offer by the local public labour exchange is dropped from the programme ${ }^{7}$. However, enforcement of these rules is largely absent. Thus, in

\footnotetext{
${ }^{4}$ Some provisions vary according to industry, worker's occupation, geographic area, etc., and underwent frequent modifications over time. We just outline the main provisions relevant to our area and period of analysis. For details, see Anastasia et al. (2004), pp. 49-64, Caruso and Pisauro (2005) and references therein.

${ }^{5}$ The firm size threshold goes up to 50 employees for firms in some branches of retail and sales and transportation.

${ }^{6}$ Those firms should have "collective redundancies", that is at least five redundancies within a period of four months.

${ }^{7}$ The appropriateness of a job offer is defined in terms of distance from residence and closeness to previous job and
} 
Table 1: Basic features of the Liste di Mobilità

\begin{tabular}{|c|c|c|c|c|c|c|}
\hline \multirow[b]{3}{*}{ Age at dismissal } & \multicolumn{6}{|c|}{ Firm's size } \\
\hline & \multicolumn{3}{|c|}{$\begin{array}{l}\text { Workers collectively dismissed by large } \\
\text { firms (> } 15 \text { employees) }\end{array}$} & \multicolumn{3}{|c|}{$\begin{array}{l}\text { Workers dismissed by small } \\
\text { firms ( } \leq \mathbf{1 5} \text { employees) }\end{array}$} \\
\hline & $<40$ & $40-49$ & $\geq \mathbf{5 0}$ & $<40$ & $40-49$ & $\geq \mathbf{5 0}$ \\
\hline $\begin{array}{l}\text { Eligibility duration } \\
(\text { years })(*)(* *)\end{array}$ & 1 & 2 & $\begin{array}{c}3(+ \text { "long } \\
\text { mobility") }(* * *)\end{array}$ & 1 & 2 & 3 \\
\hline $\begin{array}{l}\text { Monetary benefits } \\
\text { (replacement rate, } \\
\text { with a ceiling) }\end{array}$ & $80 \%$ & $\begin{array}{c}1^{\text {st }} \text { year: } \\
80 \% \\
2^{\text {nd }} \text { year: } \\
64 \%\end{array}$ & $\begin{array}{c}1^{\text {st }} \text { year: } 80 \% \\
2^{\text {nd }} \text { and } 3^{\text {rd }} \text { year: } \\
64 \%\end{array}$ & $-(* * * *)$ & $-(* * * *)$ & $-(* * * *)$ \\
\hline Rebate on SSCs & \multicolumn{6}{|c|}{ 18-24 months } \\
\hline $\begin{array}{l}\text { Benefit transfer to } \\
\text { the hiring firm }\end{array}$ & \multicolumn{2}{|c|}{$\begin{array}{c}50 \% \text { of } 1 \text { year at } \\
\text { most }\end{array}$} & $\begin{array}{l}50 \% \text { of } 2 \text { years } \\
\text { at most }\end{array}$ & - & - & - \\
\hline
\end{tabular}

(*) During the time they are enrolled in the ML, workers are allowed to engage in temporary employment while maintaining their LM status. The time spent in temporary employment spells (each one up to one year and overall up to the eligibility duration) does not affect the duration of eligibility in the Lists.

(**) In the South of Italy, the eligibility duration is extended by one year for each of the three age groups. (This feature is not relevant for subsequent empirical analyses.)

(***) Workers $\geq 50$ years old eligible for monetary benefits maintain their eligibility status even longer if they are close to being eligible for retirement benefits (the so-called "long mobility").

(****) These workers may draw the standard UI (over the period of this study, replacement rate 30\%), provided they meet the eligibility criteria for it.

practice the worker willingness to accept a job offer is not tested and a worker enrolled in the LM can refuse any job offer s/he receives, keeping his/her LM status up to the end of the eligibility period.

\subsubsection{The active component (all enrolled workers)}

As for the active component of the programme, firms hiring workers from the LM with a permanent contract enjoy an 18-month long substantial reduction in SSCs, irrespective of the amount of time spent by the worker in the LM, of his/her age and of the size of the dismissing firm. SSCs paid by the employer drop from the standard rate - in 1998 around 35\% - to the fixed amount due for apprentices, about 3\% of the standard one. Firms can also hire workers from the LM on a temporary (up to) one-year basis, this way enjoying an (up to) one-year reduction in SSCs. Lastly, firms can largely cumulate these rebates by hiring workers on a temporary one-year contract and then switching to a permanent one as the former expires: this way the rebate lasts two years.

In addition, firms hiring on a permanent contract workers eligible for monetary benefits are entitled to receive up to $50 \%$ of the residual benefit the hired worker would have received had s/he remained in the LM. The benefit transfer has a maximum equal to $50 \%$ of total amount of the monetary benefit over one (two) years, for workers aged up to (older than) 49, respectively.

As we will document shortly, incentives to the hiring firm are substantial and may induce some firms to fraudulently dismiss workers and enrol them in the LM in order to re-hire them, 
directly or by affiliates or by newly created firms, only to draw benefits. This possibility has been drastically restricted by Law No. 451/1994, which was enacted also to prevent these frauds ${ }^{8}$.

Summing up, there are in fact two separate sub-programmes targeted to two nonoverlapping populations.

(a) The first sub-programme applies to workers who have been collectively dismissed by large firms. (a1) Upon dismissal they enter LM by default and receive a monetary benefit which is partly transferred to any firm hiring them. The same firm also benefits from a rebate on SSCs for up to two years. (a2) Besides, this sub-programme is fundamentally altered for workers aged 50 or more meeting the requirements for "long mobility". For these workers the active component of the programme is largely dominated by the passive one.

(b) The second sub-programme applies to workers either collectively or even individually dismissed by small firms. They enter LM on a voluntary basis and are eligible only for the active component of the programme, which they can cumulate with the much less generous standard UI provided they are eligible to it.

The common feature of the two sub-programmes is the duration of eligibility determined by the worker's age at dismissal, a feature we crucially rely on to design our identification strategy. However, the differential effect one should expect from the packages of benefits associated to the eligibility duration is very likely to vary across sub-programmes, as well as from the 40- to the 50year threshold for workers eligible to monetary benefits.

\subsection{An example to illustrate how firms gain by hiring from $L M$}

Here we present some computations of the gain a firm can get by hiring workers from the LM. To illustrate the point, we build up on the example summarised in Figure 1. The benchmark is given by an employee hired on a permanent basis from the market, whose annual gross wage ${ }^{9}$ is approximately 13,000 Euros. This is the modal gross wage for a blue collar 40 years old in a sector such as textile in 1998.

Adding to the annual gross wage the SSCs paid by the employer, this representative worker costs approximately 34,250 Euros over two years (Figure 1, first bar on the left). To this benchmark, we compare the cost the employer incurs by hiring from the LM workers eligible for alternative packages of benefits under alternative hiring strategies.

No matter for the worker's eligibility duration, for his/her eligibility for monetary benefits and for the time s/he already spent in the LM, the best strategy for the employer is to hire a worker from the LM on a temporary one-year contract and then to switch it to a permanent one. In case the worker is not eligible for monetary benefit, this strategy provides a saving over the two years labour cost worth approximately 8,000 Euros (23\% of the labour cost; Figure 1, third bar from the left).

\footnotetext{
${ }^{8}$ Re-hiring was formally prohibited during the first six months of enrolment in LM, and the social security agency has been active in order to contrast any practice aimed at evading the law. However, some frauds still appear to occur (see Anastasia et al., 2004, for empirical evidence for the Veneto region). Moreover, some rules of the programme are still opaque - derogations were occasionally introduced to face occupational crises - and leave room for what might not be fraudulent behaviour but simply improper use of the programme: see Caruso and Pisauro (2005), who, for a region of Central Italy, provide evidence of some confusion between dismissals and temporary lay-offs. In the latter case workers are dismissed and then simply recalled to their old job, a practice that in principle should be at the margin of the scope of the programme.

${ }^{9}$ Gross of SSCs paid by workers and personal income taxes. For such a wage the ceiling for the monetary benefit to an eligible worker in the Lists is binding.
} 
Figure 1: Total labour cost and savings over two years for a hiring firm under alternative strategies of hiring a worker from the LM: some typical cases ${ }^{\text {a }}$

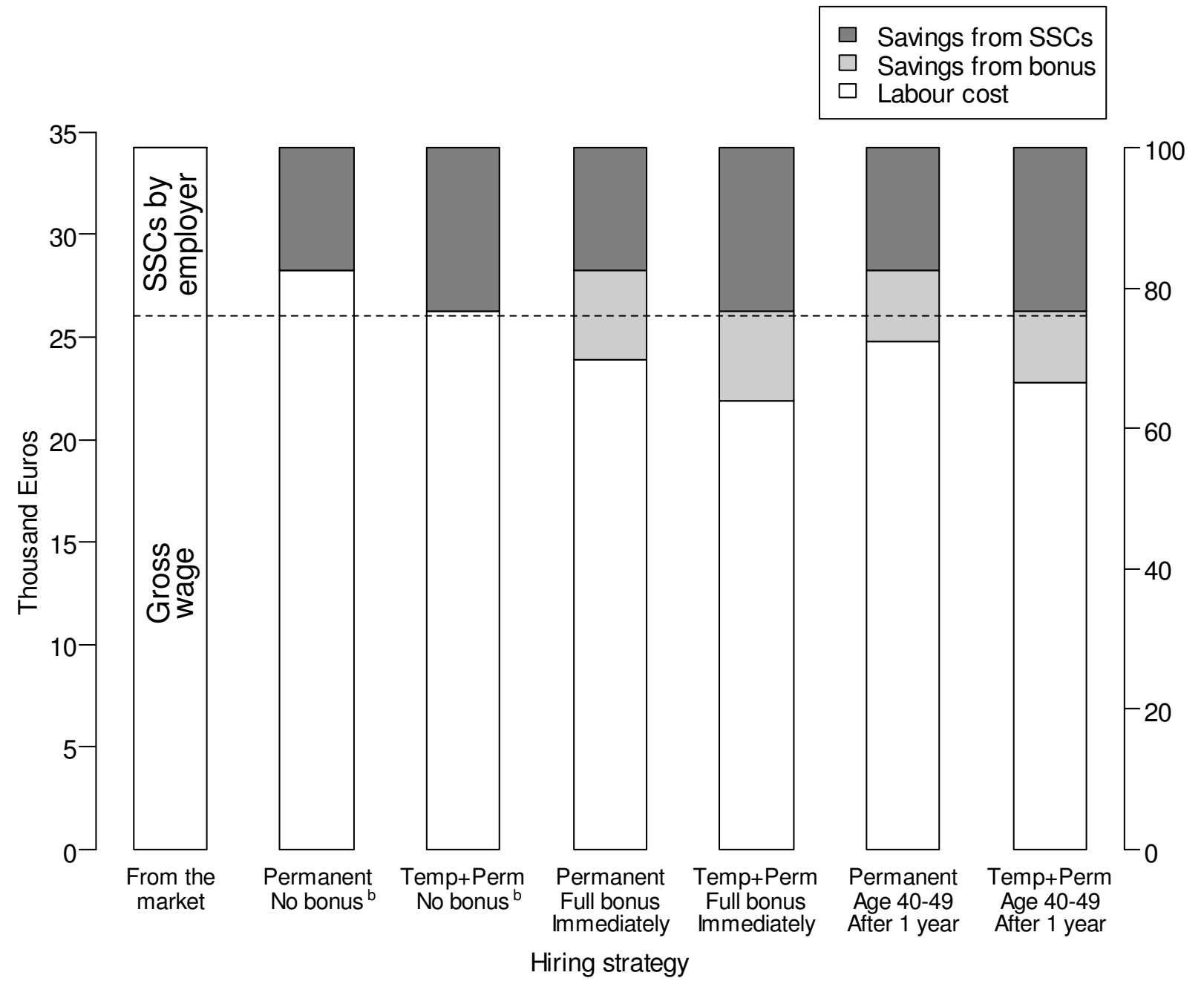

\footnotetext{
${ }^{\text {a }}$ Working assumptions: annual gross wage 13,000 Euros; SSC rates and monetary benefits ceiling effective in 1998.

${ }^{\mathrm{b}}$ Benefits when hiring (i) a worker without monetary benefits or (ii) a worker aged less then 40 with monetary benefits the last day of the first year or (iii) a worker aged 40 to 49 with monetary benefits the last day of the second year.
}

In the following of our example, variation of age of the hired worker is always meant to be around the 40-year threshold. The employer saves 4,350 additional Euros (13\% of the labour cost $)^{10}$ by hiring a worker eligible for monetary benefits on his/her first day in the LM, irrespective of the duration of his/her eligibility (Figure 1, fifth bar from the left). Note that if the worker is not eligible for monetary benefits, the employer savings on labour cost do not vary with the duration of worker's eligibility nor with the time s/he already spent in the LM. Note, further, that if the worker is eligible for monetary benefits, the employer savings on labour cost do not vary with the duration of worker's eligibility only if the hiring takes place the very first day s/he enters the LM.

\footnotetext{
${ }^{10}$ Note that the relative weight of the benefit transfer - with respect to total savings from hiring a worker from the LM - varies when the ceiling to the monetary benefit is binding, i.e. when it is lower than the $80 \%$ replacement rate. Clearly, the larger the difference between the $80 \%$ replacement rate and the monetary benefit (otherwise stated, the higher the worker's previous gross wage), the lower will be the relative importance of the benefit transfer. In our example monthly gross wage was set at 1,000 Euros, slightly higher than the threshold corresponding to the ceiling to the monetary benefit, which is therefore effective (though marginally: 725 Euros vs. the hypothetical 800 Euros implied by the replacement rate rule).
} 
Figure 2: Savings over two years for a hiring firm as a function of the time elapsed since enrolment in the ML, under the hiring strategy "first temporary-then permanent contract" of a worker entitled to monetary benefits, age $40 \mathrm{vs.} 39^{\mathrm{a}}$

2a: Total savings by age group

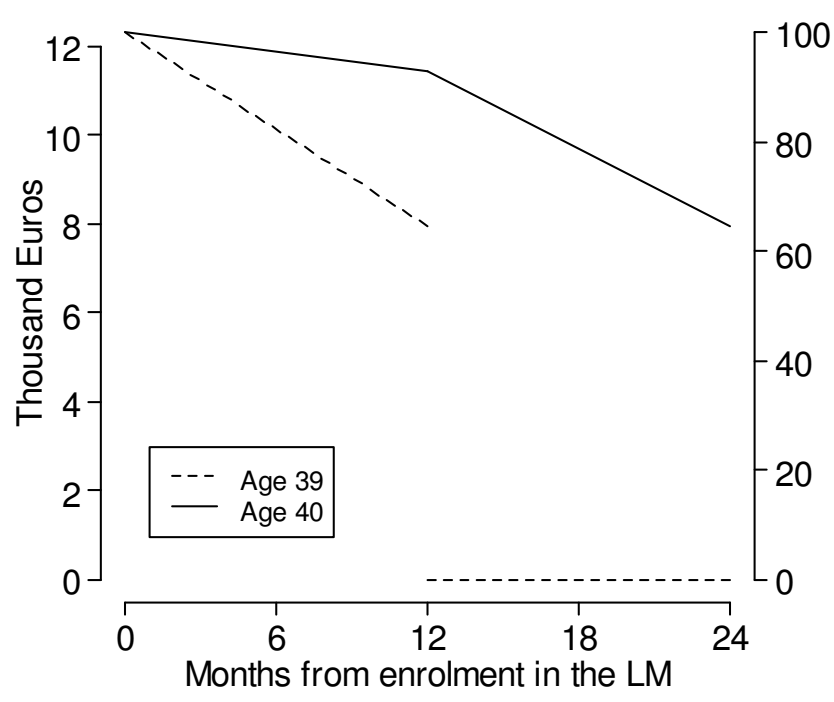

2b: Differential savings

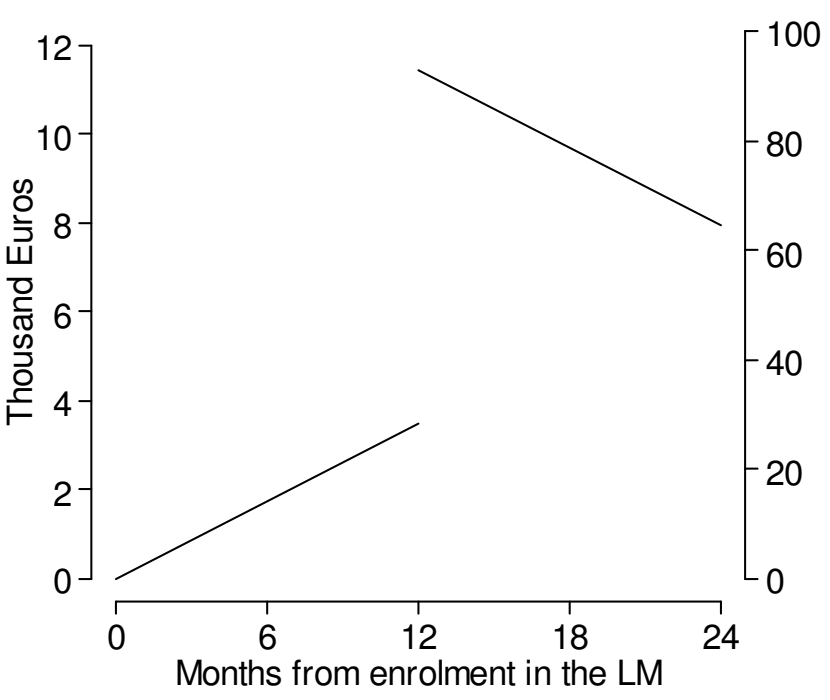

${ }^{\mathrm{a}}$ Working assumptions as in Figure 1.

As seen from the point of view of an employer who is considering to hire from the LM a worker eligible to monetary benefits, the difference between hiring a worker in the two-year regime and a comparable worker in the one-year regime becomes relevant as time spent in the LM goes by (Figure 2):

- during the first year it is as large as 3,479.(t/365) Euros, $t=1, \ldots, 365$, where $t$ is the number of days the worker has been enrolled in the LM at the time the hiring takes place. Thus it is zero the first day in the LM, then it increases linearly peaking at 3,479 Euros by the end of the year $^{11}$;

- during the second year it is as large as $\{7,968+3,479 \cdot[(1-(t-365) / 365]\}$ Euros, $t=366, \ldots, 730$, as for workers aged 39 the eligibility period expired.

From Figures 1 and 2 it is also apparent that the bulk of savings for the hiring firm is represented by the massive rebate on SSCs. In the case of the best hiring strategy just considered, it goes from $65 \%$ to $70 \%$ of total savings (when hiring a worker the first day s/he enters the LM or a worker aged 40 after one year, respectively). Besides, it coincides with total savings - by the way still substantial: $23 \%$ of the two years labour cost - in all circumstances when there is no benefit transfer, and specifically at the end of eligibility period.

One implication of these facts is that it might not be all that crucial to a potential employer whether the LM worker to be hired is entitled or not to monetary benefits, and whether s/he is above or below the 40-year threshold, because in all cases the employer receives the same rebate on SSCs, as long as the worker is eligible. The important difference for the employer is that workers below the 40-year threshold must be hired during the first year in the LM to carry the SSCs rebate with them, while workers in their forties have an additional year to be hired with the rebate.

\footnotetext{
${ }^{11}$ In relative terms, the fraction of savings is as large as $[3,479 \cdot(t / 365)] /[7,968+3,480 \cdot(t / 365)]$, and reaches a peak of $30 \%$ at the end of the first year.
} 


\subsection{LM in an international perspective}

It is worth briefly gauging the peculiar design of the LM programme within an international perspective. The core of LM programme consists of a combination of two well-established measures: an employment subsidy to the hiring firm; a monetary benefit to the worker. Besides, the policy mix varies according to workers' age at dismissal and dismissing firm size. While such variation in the policy mix is peculiar to the LM programme, the two basic ingredients - the active and the passive component - and their combination are shared by several active labour market policies in developed countries.

The cross-country comparative empirical evidence about employment subsidies suggests that they "can yield significant net employment gains and help maintain workers' attachment to the labour force. However, employment subsidies should be of short duration, targeted and closely monitored" (Martin and Grubb, 2001: 33).

There is also abundant empirical evidence that UI reduces the hazard to employment up to the time close to the expiration of the benefit (see Atkinson and Micklewright, 1991, Meyer 1990, and recently Fredriksson and Söderström, 2008, among many others). More success stories are found when UI is complemented with employment bonuses - i.e. cash payments to UI recipients who find a job quickly and keep it for a specified length of time - or with combinations of services to improve job search and increase enforcement of work search rules (Meyer, 1995).

Looking at the policy mix, a peculiar feature of the LM programme is the lack of any "activation" strategy, aimed at accompanying the two components just mentioned. As research largely documented by OECD and several other studies suggests, the synergy between the active and passive components of a labour market programme is vital if one seeks to enhance its effectiveness. From that perspective, despite its benefit transfer component the LM rests essentially a traditional programme. It does not reflect the shift in the policy stance towards greater "activation" and a tightening of the eligibility rules for benefit receipt noticeable in the last decade in many OECD countries (Martin and Grubb, 2001, OECD, 2005, Chapters 3-5, Kluve et al. 2007; specifically for the US see Blank, 2002, and Grogger and Karoly, 2005).

\section{Previous research on the LM}

Previous research on the LM has largely focused on programme participants aged less than 50 years, focusing on the causal effect of being eligible for two years vs. one year on either the duration of the unemployment spell or on the probability to be at work at selected post-enrolment periods.

A first group of studies (see Brunello and Miniaci, 1997, and Paggiaro and Trivellato, 2002, among others ${ }^{12}$ ) have exploited regional administrative data resulting from the programme operations for Lombardy - a large region around Milan - and Veneto - the region around Venice, respectively. Because of data constraints, the only outcome variable they consider is the waiting time to a permanent job. As for the identification strategy, they rely on (semi-)parametric specifications of models for transitions in a two-state space: registered in the LM or permanently hired. They use multiplicative hazard models, with a polynomial in age in order to control for age. Even in the case of a flexible semi-parametric specification, with a piecewise exponential for the baseline hazard and unobserved heterogeneity à la Heckman and Singer (1984) ${ }^{13}$ (Paggiaro and

\footnotetext{
${ }^{12}$ See Anastasia et al. (2004) for a survey of data, methods and main results of this first generation of studies.

${ }^{13}$ The inclusion of unobserved heterogeneity is patently irrelevant for estimating the differential effect of two years $v s$. one year eligibility. However, it is useful for better estimating the shape of the baseline hazard, specifically its spikes at the end of the first and second year.
} 
Trivellato, 2002), eventually one is left wondering how much results depend on the particular parametric specification assumptions, and to which particular sub-population they refer to ${ }^{14}$.

A more recent strand of studies uses more informative data sets from administrative archives resulting from the operations of public labour exchanges, which provide detailed information on work histories and some additional demographics. Caruso and Pisauro (2005) deal with workers from the LM of a small region of central Italy. Paggiaro, Rettore and Trivellato (2005) and Martini, Martini and Mo Costabella (2007) analyse workers in the Lists from various provinces of Northern Italy. Their outcome variable is the monthly re-employment rate during the three years after enrolment in the LM, which allows to observe what happened during enrolment and after leaving the LM for most workers, irrespective of the type contract - temporary or permanent - firms use to hire a worker form the Lists. They identify the effect of the additional year of eligibility on reemployment probabilities via propensity score matching, using both individual characteristics and past work histories. Unfortunately, conditional on available information (quite rich indeed), evidence from a test on the ignorability assumption, implied by matching methods, suggests that these methods are not entirely successful in controlling for the age effect ${ }^{15}$.

As for the substantive results from these studies, the prevailing evidence can be summarised in two statements: (i) for workers entitled only to the active component of the LM, i.e. dismissed by small firms, there is no effect of the additional year of eligibility on re-employment probabilities and on the time spent waiting for the first permanent job; (ii) for workers entitled also to monetary benefits, i.e. dismissed by large firms, the additional year of eligibility has a negative impact: older workers, who draw benefits longer, have significantly lower re-employment probabilities - and a significantly lower hazard to the first permanent job - than their younger colleagues. This effect tends to be larger for women, but not consistently across all the case-studies.

\section{What are the likely effects of extending the eligibility period?}

We address the question by focusing on the differential effect of being eligible for two years in the LM instead of just one. The issue can be formulated as follows: in which direction does allowing workers just above the 40-year threshold to stay in the programme for two years affect their chance of re-employment relative to what would happen to them with a one year eligibility?

With the standard job search model as a background (Mortensen and Pissarides, 1999), it is apparent that there are two contrasting incentives stemming from the LM programme: (i) the incentive to firms, which benefit from the rebate on SSCs (and in some cases from the benefit transfer), to provide workers enrolled in the LM with more job offers that they would otherwise receive; (ii) the incentive to workers drawing monetary benefits from the LM programme to lengthen their unemployment spell by increasing their reservation wage, then to refuse the job offers they receive, at least over a large fraction of their eligibility period.

In comparative terms, both these incentives tend to be higher under the two-year regime than under the one-year one. From a theoretical point of view, the sign of the differential treatment effect is a priori uncertain, and depends on which of the two incentives prevails. Furthermore, it will

\footnotetext{
${ }^{14}$ In the presence of impact heterogeneity, by design only the mean impact of the second year on workers marginally eligible for the second year, namely those aged 40, is intrinsically identifiable. The intuition is straightforward: the variability in the treatment status - two years vs. one year - the analyst needs in order to identify the impact of the treatment, is available only in the sub-sample of workers whose age is in a neighbourhood of 40. If the impact varies with age, there is no way to identify the mean impact for individuals away from the threshold, so strictly speaking the results they got refer to workers marginally eligible for the second year.

15 The test consists of splitting controls (and treatments) in two age sub-groups and checking whether the mean outcomes in the two sub-groups resulting after matching differ (see Paggiaro, Rettore and Trivellato, 2005).
} 
inextricably mix with the provisions about engagement in temporary employment. Thus, the differential treatment effect can only be sorted out empirically.

\section{The design of the evaluation study}

To begin with, in the following analyses we exclude the possibility of general equilibrium and spill-over effects of the programme. The average yearly flow of workers enrolled in the LM less than 8,000 - is still a modest fraction of the average stock of unemployed in the region around 100,000, which suggests that effects of the programme on unemployed workers ineligible to the LM as well as on the functioning of the labour market should be negligible.

By exploiting the institutional rules of the programme, we can identify the causal effect of extending the duration of eligibility by one year at the 40- and 50-year threshold, respectively ${ }^{16}$. Here we illustrate our identification strategy with reference to the 40 -year threshold. The extension to workers at the 50-year threshold is operationally straightforward, though the interpretation of results for workers entitled to monetary benefits has to take into account that, actually, the treatment includes not only an additional year of eligibility but also the bridge to retirement.

Since the duration of the eligibility period is deterministically assigned on the basis of worker's age at dismissal, when comparing workers assigned to the two-year regime to those receiving the alternative one-year regime the econometric problem we face is how to disentangle the causal effect of the second year of eligibility from a pure age affect. Let the treatment $I$, denoting eligibility to the second year, be defined as:

$$
I=\left\{\begin{array}{l}
1 \text { age } 40-49 \\
0 \text { age } \leq 40
\end{array}\right. \text {. }
$$

The outcomes we look at are the employment state of workers enrolled in the LM in each of the 36 months subsequent to their enrolment, as well as their wages at the end of that observation window. Let $Y^{T}$ and $Y^{N T}$ be the potential outcomes a specific worker would experience being exposed to and denied the treatment, respectively. By contrasting the mean outcome experienced by the treatment group to the mean outcome experienced by the comparison group, we obtain the following identity:

$$
E\left[Y^{T} \mid I=1\right]-E\left[Y^{N T} \mid I=0\right]=E\left[Y^{T}-Y^{N T} \mid I=1\right]+\left\{E\left[Y^{N T} \mid I=1\right]-E\left[Y^{N T} \mid I=0\right]\right\},
$$

where $E\left[Y^{T}-Y^{N T} \mid I=1\right]$ is the average treatment effect on the treatment group (ATT), and the difference in brackets is the selection bias induced by the differential composition of the two groups with respect to age.

Since it is known that assignment to the treatment deterministically depends on age, by conditioning on age $=40$ - the only point in the age support around which there are both individuals assigned to the two-year regime and individuals assigned to the one-year regime - the selection bias becomes:

\footnotetext{
${ }^{16}$ Here we do not address the issue of identifying the causal effect of being eligible to monetary benefits - an interesting, and classical, evaluation question - for two reasons. First, there are many studies which have looked on effects of the unemployment benefit system, in more detail and with more informative data sets (some references are in Section 2.4 above). Second, and more important, in our case the firm size threshold of 15 employees, which discriminates about eligibility to monetary benefits, is relevant for several other discontinuities in Italian labour market regulations (see Section 2.1 above). This raises a hardly solvable identification issue, because workers hired by small firms may be different in many unobservable ways from workers employed by larger firms (see Paggiaro, Rettore and Trivellato, 2005: 16-17).
} 


$$
E\left[Y^{N T} \mid I=1, \text { age }=40\right]-E\left[Y^{N T} \mid I=0, \text { age }=40\right],
$$

which we restrict to be zero to identify the ATT at age $=40$. This is the classic sharp RDD identifying restriction, stating that the conditional mean $E\left[Y^{N T} \mid\right.$ age $]$ is a continuous function of age in a neighbourhood of age $=40$ (see Hahn, Todd and Van der Klaauw, 2001). The drawback of this design is that if the programme impact is heterogeneous across subjects - as it is likely to be in most cases, then it only allows to identify the ATT in a neighbourhood of the threshold. As Imbens and Lemieux (2008: 628) put it, "the design has fundamentally only a limited degree of external validity, although the specific average effect that is identified may well be of special interest".

The internal validity of our identification strategy rests on the assumption that if individuals just above and just below the threshold were assigned to the same eligibility regime they would experience the same average outcome. Clearly, any evidence providing support to this claim would be most welcome, also because, at least in principle, one could imagine reasons why the assumption might be violated. For instance, one could argue that workers enrolled in the LM and above the threshold are on average worse, from the employer point of view, than those just below the threshold. This could happen if firms and unions bargain on the composition of the pool of workers to be dismissed, with unions taking into account the income prospects of workers, which include both their expected earnings $(w)$ and the benefits $(b)$ they would get from the LM. If the union rule to accept to include a worker in the list is $w+b>c$, with $c$ a suitable threshold common to all workers, then dismissed workers entitled to a more generous monetary benefit will feature on average a lower $w$ than dismissed worker entitled to a poorer benefit.

Some evidence that selection of workers to be put into the LM might have taken place, based also on the LM benefits they are entitled to, comes from Figure 3. It shows the distribution of enrolled workers by age, entitlement to monetary benefits and gender. The main evidence is a large discontinuity at the 50-year threshold for men with monetary benefits. As this is the threshold at which most of the workers get the entitlement to "long mobility", it could be the case that workers dismissed by large firms has been chosen considering also the peculiar differential advantages brought to workers by the "long mobility" provisions.

A further reason for a possible violation of the RDD restriction comes from the differential rate of success of the linkage between the two archives we got our data from (see Figure 4 and related comments below) ${ }^{17}$.

Following Lee (2008) we carry out a set of overidentification tests to validate our RDD. The tests are based on comparing individuals just above the threshold to their younger collegues just below it with respect to their pre-programme employment history. Since it is hard to think of a causal effect of the LM programme on the employment state and on wages experienced by a worker three years, say, before entering the LM, any discontinuity at the cut-off points should be interpreted as a sign of a differential composition around the cut-off point with respect to characteristics relevant for subsequent employment state and wages. Hence, as an evidence against the validity of the RDD restriction.

As for the estimation of the ATT, it translates into the problem of estimating the conditional expectations of the two potential outcomes at the threshold. We use a local linear regression (LLR)

\footnotetext{
${ }^{17}$ In this case, however, some hints on the direction of the possible bias come from collateral information we got from the labour exchange archive. The linkage process essentially misses workers who are not observed to find a new job during enrolment in the Lists. As a consequence, the true employment rate for workers over 50 with monetary benefits is lower than the one we observe in the linked sample. Thus, the huge differences we will observe between those entitled to retirement and their younger colleagues should be considered as a lower bound of the true effect.
} 
Figure 3: Age distribution of workers enrolled in the LM in Veneto, years 1995 to 1998 , by entitlement to monetary benefits and by gender
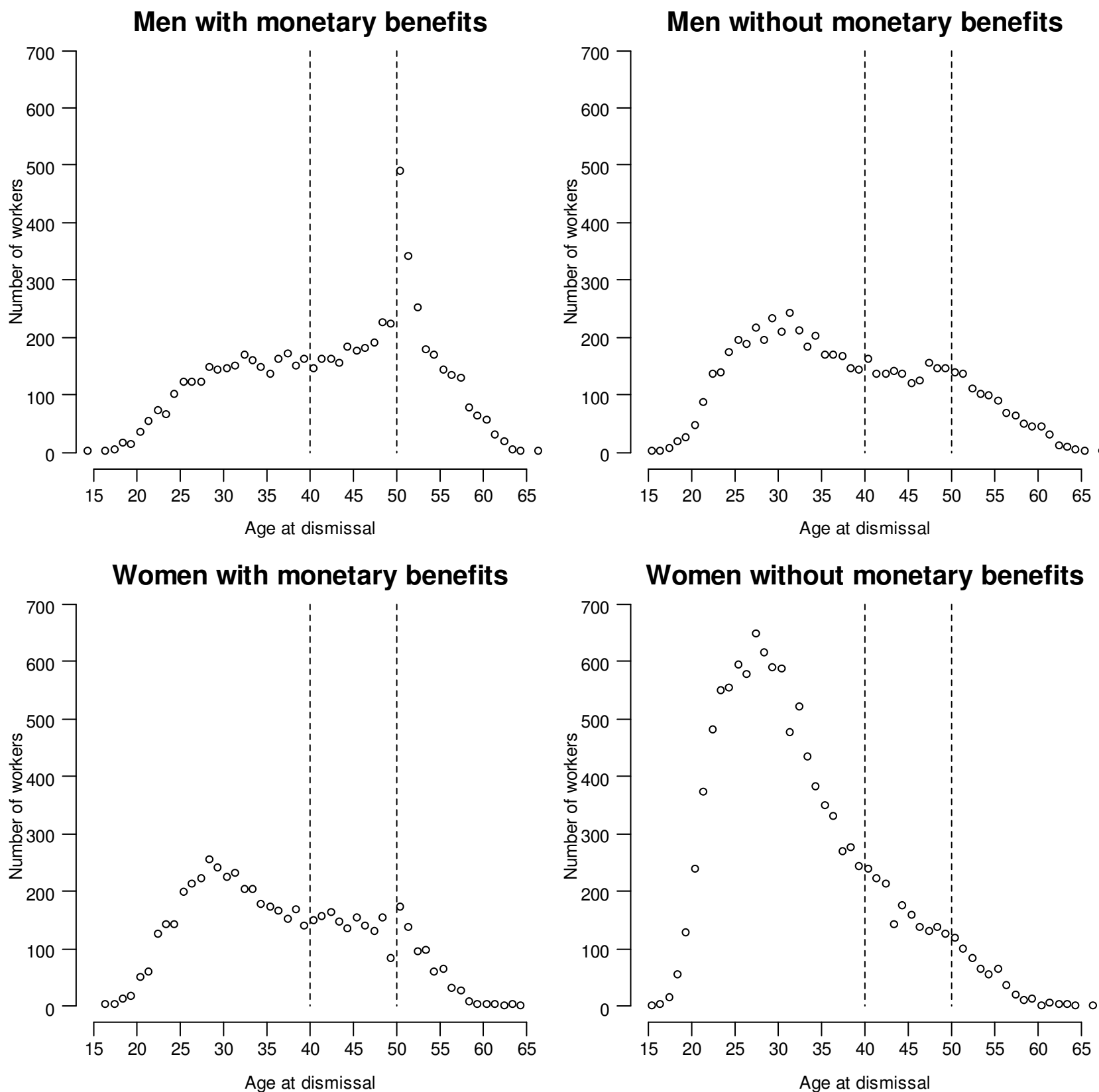

to estimate these conditional expectations, as proposed by Hahn, Todd and Van der Klaauw $(2001)^{18}$. Weights to estimate local polynomials follow a tricube function (Cleveland, 1979), while the bandwidth is chosen by using a version of the AIC criterion as proposed by Hurvich and Simonoff (1998). Confidence intervals are derived following Cleveland and Grosse (1991), who show that LLR estimates have a $t$ distribution and derive a method to calculate degrees of freedom. Thus, confidence intervals are wider and have a better coverage as compared to the usual normal approximation, particularly in the presence of a limited sample size.

\footnotetext{
${ }^{18}$ We carried out a sensitivity analysis changing the parameters of the LLR as well as using alternative methods such as splines and simple parametric methods. The evidence we got is robust to these alternatives.
} 


\section{The empirical study}

\subsection{Data}

We carry out our analyses on the population of workers enrolled in the LM in the Veneto region in the years 1995 to $1998^{19}$. Veneto is a well-developed region, with a rather tight labour market and a per capita GDP some $15 \%$ higher than the national average. In 1998, the employment rate was $59.6 \%$ compared to $52.9 \%$ in Italy, and the unemployment rate was $6.1 \%$ vs. $11.4 \%$ in the whole country ${ }^{20}$. Thus, while our main results would reasonably generalise to most of Northern and Central Italy, who feature not so dissimilar rates of employment and unemployment, they by no means can be taken as representative of the whole of Italy ${ }^{21}$.

The list of workers we started from comes from an ad hoc file from the public labour exchange archive. To this set of records we linked records from INPS - the Italian social security agency - archives. This way we get a rich description of employment histories and wages from 1975 to 2001. The file resulting from the linkage covered $93.3 \%$ of the original population of workers enrolled in the LM (the few missing cases are presumably due to errors in the ID key we rely on to link the two archives). Out of this file, after some consistency checks across the two archives on the dates of enrolment in the LM we end up with a sample of 23,644 enrolled workers, i.e. $80 \%$ of the original population.

Figure 4 presents the rate of inclusion in the final sample by age for the four sub-groups defined by entitlement to monetary benefits and gender. The only noticeable evidence is a discontinuity at the 50-year threshold for workers drawing monetary benefits, with older workers exhibiting a significantly lower rate. In Section 6.2 we provide an assessment of the bias possibly resulting from this differential sample selection.

Our data set improves over those used by previous analysts of the LM in several respects. It provides a detailed description of the labour market history of enrolled workers, including temporary employment spells, over a wide time window extending from several years before enrolment to three years after it. This is important for two reasons: (i) we exploit the preprogramme history to validate our identification strategy; (ii) we can assess the medium range effect of the programme. Finally, we are now in the position to measure the programme impact on wages, which was entirely missing in all previous studies.

The analysis is systematically carried out separately (i) for the two LM sub-programmes, (ii) by gender, and (iii) at the 40-year and 50-year threshold. Table 2 shows the breakdown of workers by entitlement to monetary benefits, gender and age group:

- Workers aged less that 40 years are two out of three. The fraction goes up to $81 \%$ among women without monetary benefits, who represent more than half of the whole age group. 59.5\% of the workers are not entitled to the LM monetary benefits, i.e. they have been dismissed by small firms. This proportion is particularly large among women.

\footnotetext{
${ }^{19}$ In principle data are available from 1991 - the year when the programme started - to 2001. We restrict our analysis to workers enrolled between 1995 and 1998 because (i) the quality of the labour exchange archive for the years 19911994 is poor, and this way (ii) for each worker we have at least three years of post-enrolment labour market history, which is crucial for estimating the medium term effect of the programme.

${ }^{20}$ Employment rate is defined with reference to the population aged 15-64. These data, as well as those on unemployment, are revised official estimates from the Labour Force Survey. Comparative empirical evidence for adjacent years is similar.

${ }^{21}$ The main reason for that is the comparatively poor situation of Southern Italy in terms of both GDP and employment. Besides, the LM programme itself it differentiated for workers residing in Southern Italy. As pointed out in Table 1, footnote $(* *)$, for them, the length of the eligibility period is further extended by one year, for all age groups.
} 
Figure 4: Rate of successful linkage between the INPS and the labour exchange archives by age, by entitlement to monetary benefits and by gender (LLR estimates and $95 \%$ confidence intervals)
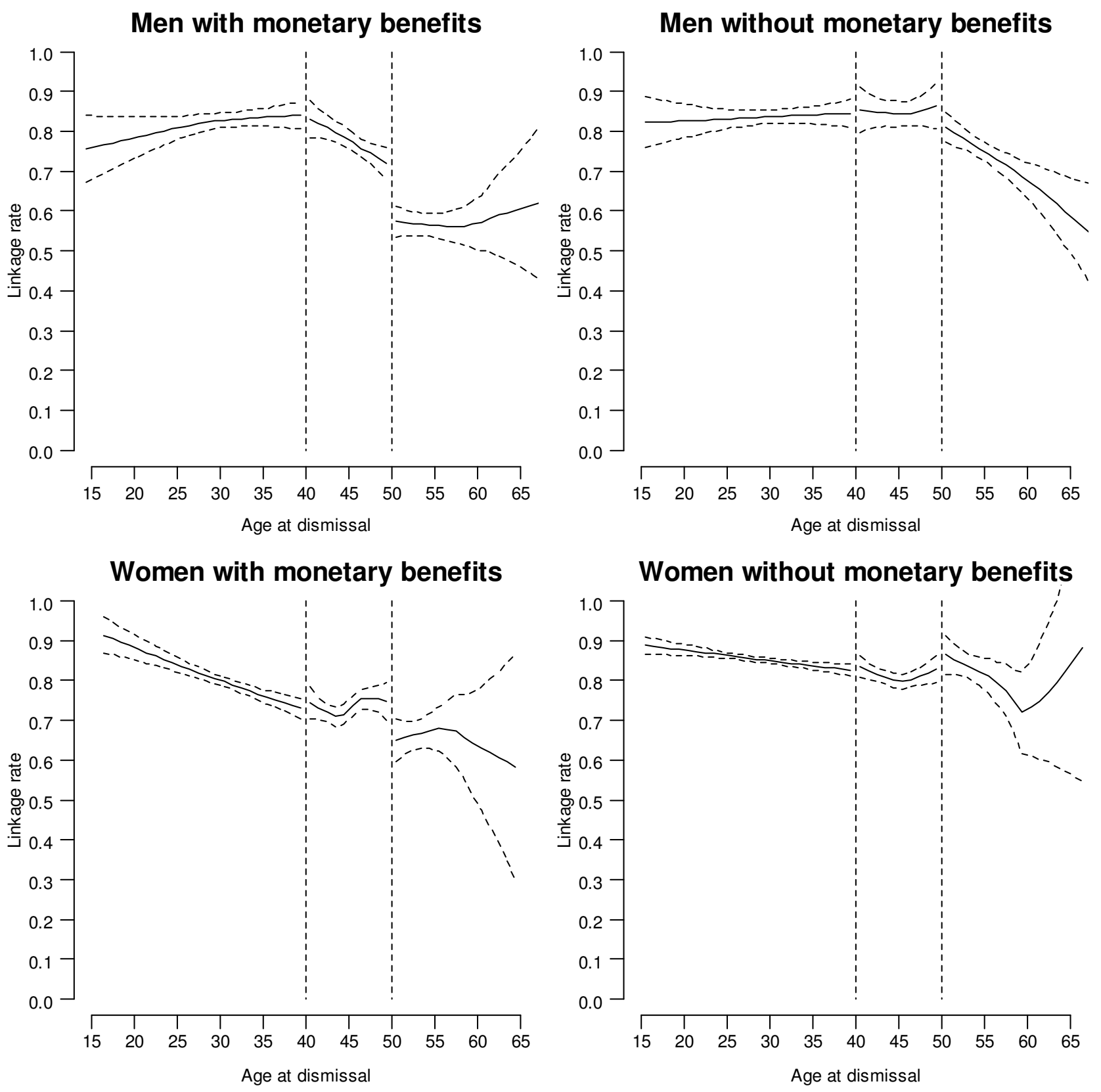
Table 2: Workers enrolled in LM in Veneto, years 1995 to 1998, by gender, entitlement to monetary benefits and age group

\begin{tabular}{|c|c|c|c|c|c|c|c|c|c|c|}
\hline \multirow[b]{2}{*}{ Age } & \multicolumn{2}{|c|}{$\begin{array}{c}\text { Men } \\
\text { with } \\
\text { monetary } \\
\text { benefits }\end{array}$} & \multicolumn{2}{|c|}{$\begin{array}{c}\text { Men } \\
\text { without } \\
\text { monetary } \\
\text { benefits }\end{array}$} & \multicolumn{2}{|c|}{$\begin{array}{c}\text { Women } \\
\text { with } \\
\text { monetary } \\
\text { benefits }\end{array}$} & \multicolumn{2}{|c|}{$\begin{array}{c}\text { Women without } \\
\text { monetary } \\
\text { benefits }\end{array}$} & \multicolumn{2}{|c|}{ Total } \\
\hline & $N$ & $\%$ & $N$ & $\%$ & $N$ & $\%$ & $N$ & $\%$ & $N$ & $\%$ \\
\hline$<40$ & 2,127 & 45.2 & 2,929 & 60.2 & 2,808 & 65.1 & 7,921 & 81.1 & 15,785 & 66.7 \\
\hline $40-49$ & 1,392 & 29.6 & 1,185 & 24.4 & 1,037 & 24.1 & 1,366 & 14.0 & 4,980 & 21.1 \\
\hline$>49$ & 1,183 & 25.2 & 751 & 15.4 & 465 & 10.8 & 480 & 4.9 & 2,879 & 12.2 \\
\hline Total & 4,702 & 100.0 & 4,865 & 100.0 & 4,310 & 100.0 & 9,767 & 100.0 & 23,644 & 100.0 \\
\hline
\end{tabular}

- The number of women above the 50-year threshold and entitled to the LM monetary benefits is rather small. Results on this group will be quite imprecise.

As for the outcome variables, the employment state of the $i$-th individual in month $t$ is set to one if s/he works at least one paid week during that month, and zero otherwise. As for the worker wage, we move from each of the spell- and (calendar) year-specific gross payments the worker receives and divide them by the number of weeks at work s/he experiences in the corresponding periods $^{22}$. Then we attach to each month the typical weekly gross wage of that month.

\subsection{Specification tests on the RDD identifying restriction}

Figure 5 plots the employment rate by age for workers enrolled in the LM three years before enrolment $^{23}$. No significant discontinuity appears at the cut-off points. Similar evidence comes from Figure 6 for the weekly wages of workers enrolled in the LM and at work three years before enrolment. As a result, the mean value of wages three years before enrolment - namely, the product of mean wages for those working by the probability to be at work - is the same across the cut-off points. This confirms that workers aged 39 and 40, as well as workers aged 49 and 50, had the same employment history before entering the programme.

Since the unobservables relevant for the labour market outcomes experienced by enrolled workers are likely to be stable over time, we take this evidence as a validation of our identifying restriction asserting that marginal individuals assigned to alternative eligibility regimes are equivalent in all relevant respects.

\footnotetext{
${ }^{22}$ Each record in the INPS file represents a yearly social security spell, and contains the number of worked days and weeks, a sequence of 12 monthly dummies identifying month(s) in which the spell took place, and total wage. Thus, an uninterrupted working spell longer than one year is split up in several yearly spells to which the corresponding yearly wage is associated. Moreover, during a specific year more than one record is observed for workers experiencing multiple job spells (a rare exception being the case of workers holding simultaneous, mainly part-time, job positions). Wages are recorded as gross pay in Euros for the year-spell considered. Preliminary analyses suggested that the best way to identify the spell length is the number of worked weeks (number of days is definitely less reliable, as documented by many null or inconsistent values).

${ }^{23}$ Similar results hold for employment rates both one and two years before enrolment. See Figures 7 and 8 below for details.
} 
Figure 5: Employment rate three years before enrolment in the LM, by age, by entitlement to monetary benefits and by gender (LLR estimates and 95\% confidence intervals)
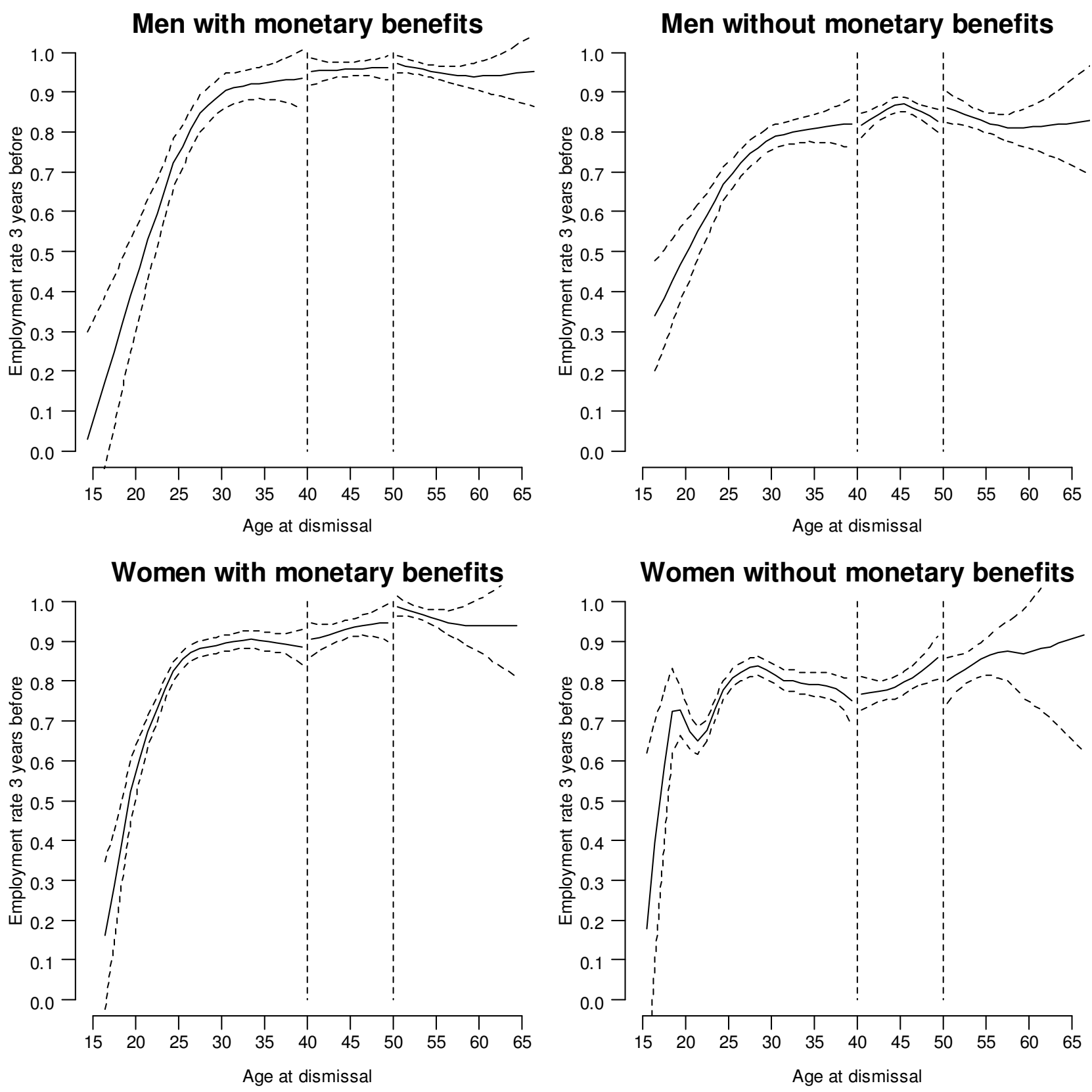
Figure 6: Average gross weekly wage (1,000 Euros 2003) three years before enrolment in the LM, by age, by entitlement to monetary benefits and by gender (LLR estimates and $95 \%$ confidence intervals)
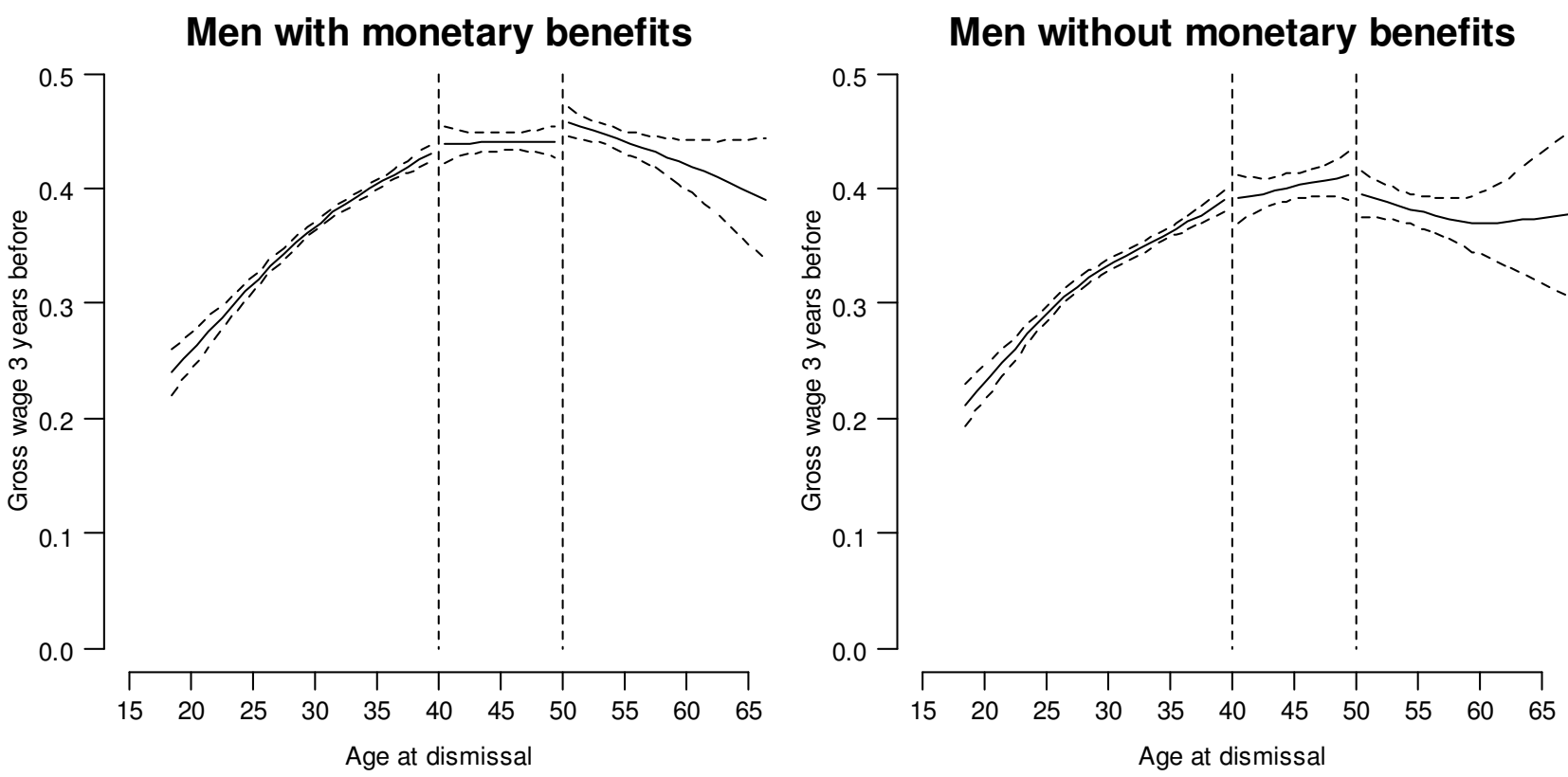

Women with monetary benefits

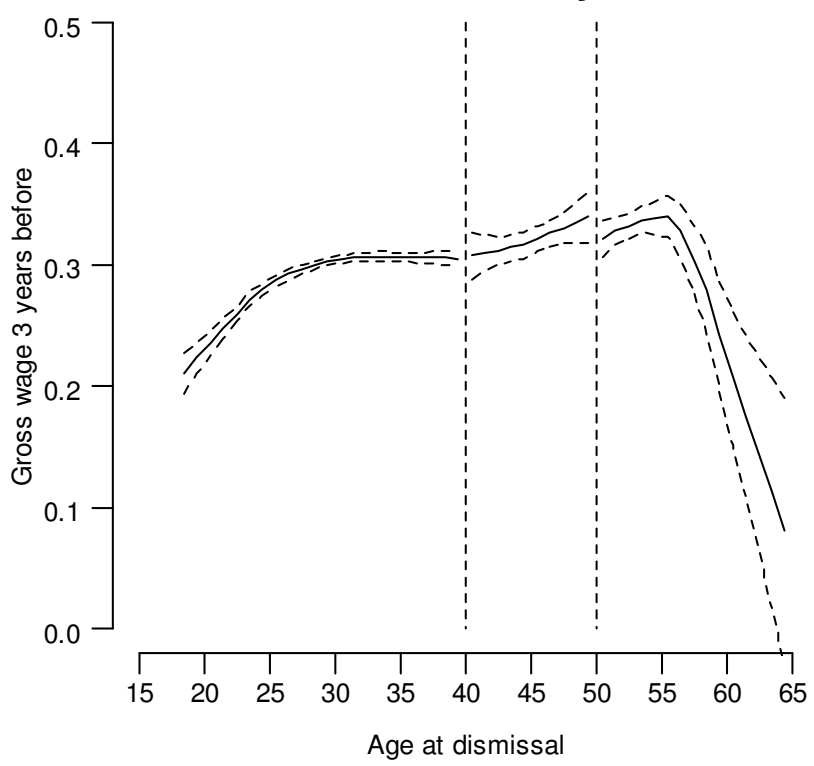

Women without monetary benefits

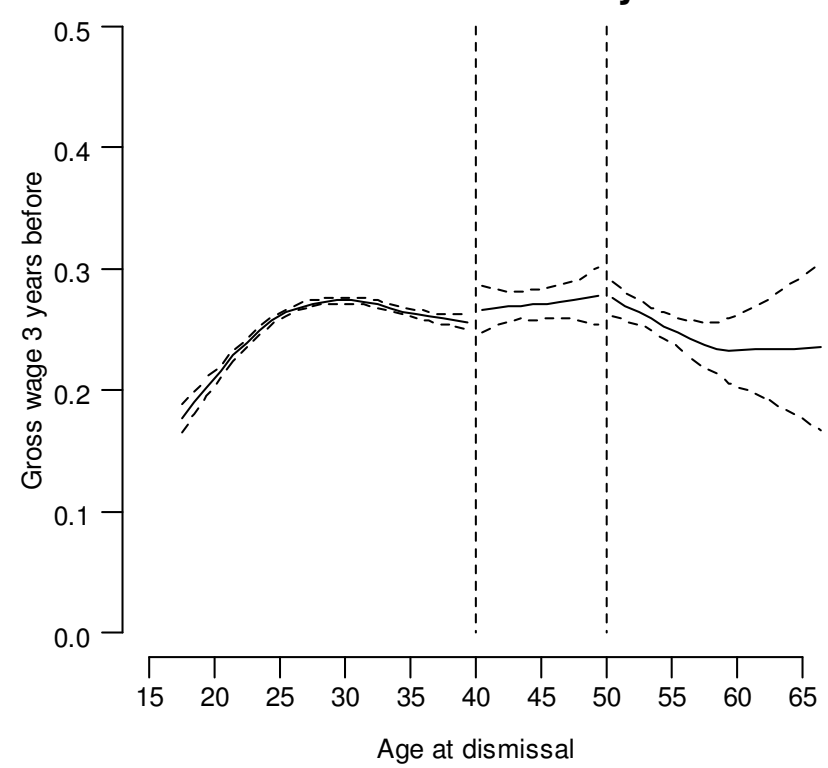




\subsection{The impact on re-employment probabilities}

Figure 7 shows the age profile of the re-employment probability three years after enrolment, thus when most workers already dropped out the LM. Compared to Figure 5, the age profile is much different, with an essentially decreasing pattern. This happens because we are now conditioning on workers who previously held a permanent job they have been dismissed from, while before enrolment younger ones might have been searching for their first job. The age profile shows no significant discontinuities at the thresholds, except for a major drop at 50 years for workers with monetary benefits, exactly those who can use "long mobility" as a bridge to retirement: the drop is as large as $32.6 \%$ for men, while it is $27.1 \%$ for women.

Figures 8 and 9 show the re-employment probabilities at the 40- and 50-year thresholds, respectively, in each of the months from -36 to 36 , estimated using the same LLR algorithm as before. Over the three pre-programme years there is no difference between groups assigned to alternative eligibility regimes. This is in line with the evidence from Figure 5.

As for the post-programme years, Figure 9 shows an increasing pattern of employment rates at the 40-year threshold for all workers, with a much steeper growth for workers without monetary benefits $^{24}$. No evidence of a causal effect of the additional year of eligibility emerges at this age threshold uniformly over time, except for women with monetary benefits. For them, during the first year after enrolment employment rates are approximately the same in the two treatment arms. However, starting from the $12^{\text {th }}$ month they keep to quite different paths. The employment rate of women marginally eligible to one year in the LM steadily grows to reach $65 \%$ by the end of the second year. On the other hand, the pattern of employment rate for women marginally eligible to two years in the LM stays approximately flat during the second year at a 50\% level. By the end of the second year the difference between the employment rates of the two groups is as large as $15.3 \%$, statistically significant. Then, employment rates for women over 40 start growing again during the third year, and at the end of it the difference between the two groups becomes statistically not significant. Thus, at the 40-year threshold the additional year of eligibility does have a causal effect on the way women entitled to monetary benefits re-enter at work: even if there is no significant effect on the probability of re-employment three years after enrolment, entitlement to longer monetary benefits makes some of them delay their re-entry at work.

The causal effect at the 50-year threshold, as shown in Figure 9, confirms for the whole post-enrolment period the results we already got from Figure 7 at the $36^{\text {th }}$ month. The causal effect of the additional year of eligibility is uniformly negative over time, but never statistically significant for workers without monetary benefits. On the other hand, a dramatic negative impact emerges uniformly over time for workers entitled to monetary benefits. The causal effect increases over time both for men and women. After one year it is as large as $28 \%$ for men and $15 \%$ for women, and grows to approximately $33 \%$ and $27 \%$, respectively, by the end of the third year.

Summing up, we observe a large medium term negative effect on employment rates at the 50-year threshold for workers entitled to "long mobility", that is workers using the LM as a bridge to retirement ${ }^{25}$. For all the other workers, whether entitled to monetary benefits or not, the probability of being re-employed after three years does not depend on the length of the eligibility period they are entitled to. Finally, there is a noticeable short term effect for women with monetary benefits at the 40-year threshold: the additional year of eligibility makes them re-enter at work quite

\footnotetext{
${ }^{24}$ We stress again that we cannot give any causal interpretation to the difference emerging from the comparison between these workers and workers eligible to monetary benefits. See footnote 16.

${ }^{25}$ Note that, as we pointed out in footnote 17, the sample selection process is likely to bring on an overestimate of employment rates for workers older than 50, so that our estimate of the causal effects can be taken as a lower bound for the true one.
} 
Figure 7: Employment rate three years after enrolment in the LM, by age, by entitlement to monetary benefits and by gender (LLR estimates and 95\% confidence intervals)
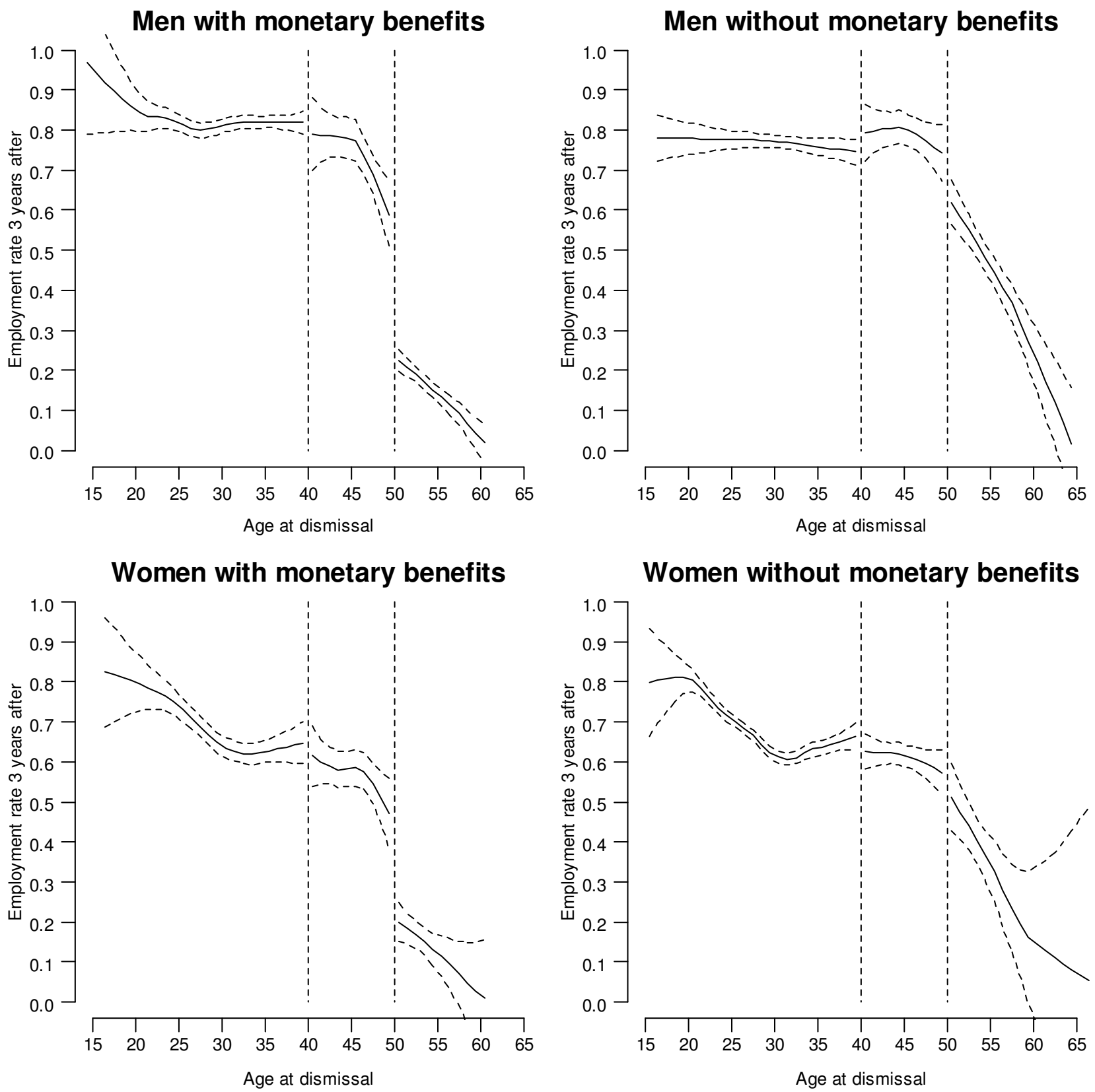
Figure 8: Employment rate at the 40-year threshold 36 months before to 36 months after enrolment in the LM, by entitlement to monetary benefits and by gender (LLR estimates and $95 \%$ confidence intervals)
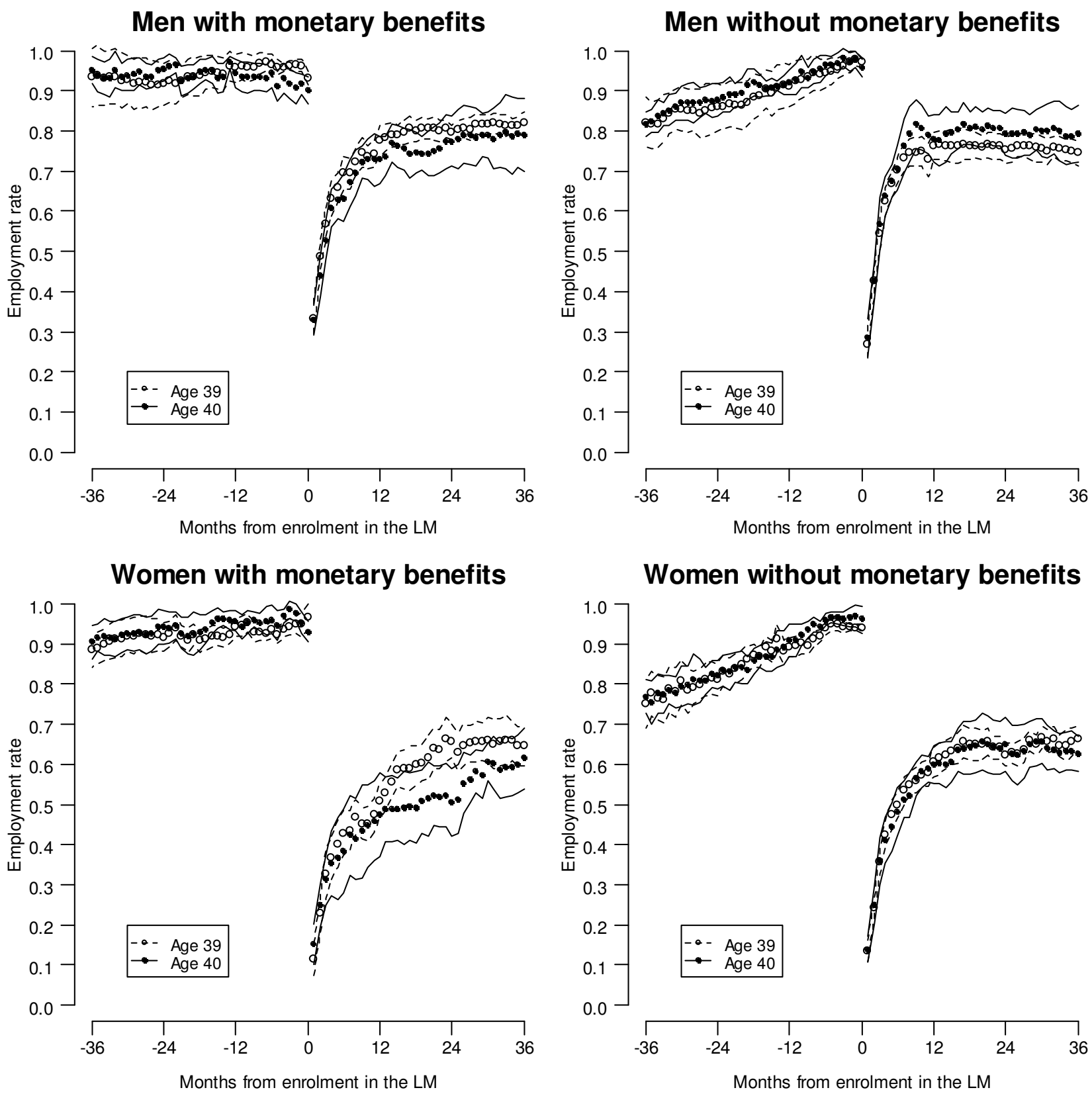
Figure 9: Employment rate at the 50-year threshold 36 months before to 36 months after enrolment in the LM, by entitlement to monetary benefits and by gender (LLR estimates and 95\% confidence intervals)
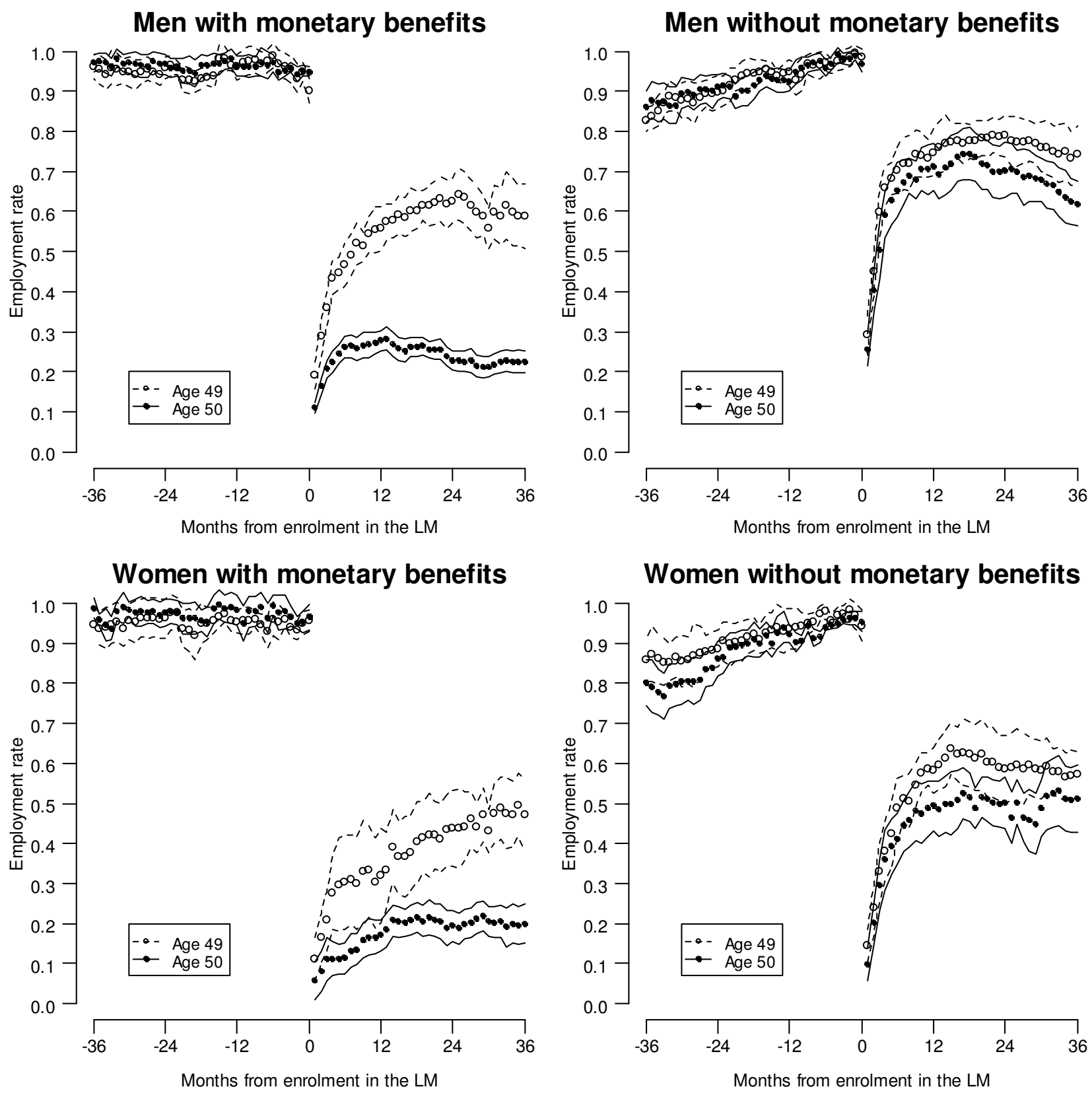
a lot more slowly, so that by the end of the second year their employment rate is some $15 \%$ lower than in the comparison group. In the next section we shall characterize the peculiar sub-group of women driving this average effect.

\subsection{The impact on wages}

We address now the issue of whether the additional year of eligibility has any effect on wages, once a worker enrolled in the LM gets a new job. Still with the standard job search model as a background, it might well be the case that entitlement to a longer eligibility period allows the worker, particularly if s/he draws monetary benefits, to be more selective during the job search, this way ending up with a higher wage. This issue raises an additional econometric problem pointed out by Ham and Lalonde (1996). Wages in any post-programme month are observable only for individuals at work on that month. If the programme has a causal effect on the composition of the pool of individuals at work on that month, then average wage among workers in the treatment group might be different from the corresponding average wage in the comparison group only because the two groups are not equivalent with respect to characteristics relevant for wages.

We test for this possible differential composition by comparing the two groups - i.e. individuals at work in the $t$-th post-programme month belonging to the treatment and the comparison group, respectively - with respect to some pre-programme features of their labour market history. Exactly the same way as for the tests on the validity of the RDD identifying restriction we presented above, any evidence of a discontinuity in the average value of such preprogramme outocomes at the 40-year and 50-year threshold would cast serious doubts on the balancing of the two groups with respect to unobservables relevant for the post-programme wage.

Conditioning on individuals at work 36 months after enrolment, Figures 10 and 11 show no evidence of significant discontinuities both for employment rates and for wages three years before enrolment $^{26}$. There is a weak evidence of discontinuity at the 50-year threshold, albeit not significant, among individuals receiving monetary benefits in the employment rate (only women) and in wages (both men and women). The overall evidence supports the conclusion that the groups we are willing to compare, to identify the causal effect of the additional year of eligibility on wages, are indeed comparable.

Figure 12 presents the estimated effect on weekly wages three years after enrolment. It shows no significant effects for all groups we consider. The only loose difference one can notice in this picture is again at the 50-year threshold both for men and women with monetary benefits. However, this difference is hardly significant and of the same size of the one we observed for wages three years before enrolment (see Figure 11). Overall, the evidence we get is that the additional year of eligibility bears no impact on wages three years after enrolment in the LM.

The final evidence we consider is on the impact of the additional year of eligibility on the quantiles of the weekly wage distribution. Figure 13 presents the estimates of selected quantiles of the wage distribution by age three years after enrolment. No relevant discontinuity appears at the 40- and 50-year thresholds for any of the quantiles we consider, with the only exception of the $9^{\text {th }}$ decile for workers with monetary benefits at the 50-year threshold. It is clear from this picture that the larger average wage we observed in Figure 11 at this threshold for workers eligible for the three-year regime is entirely due to a longer right tail of the distribution ${ }^{27}$. The men $9^{\text {th }}$ deciles are as large as 608 Euros (standard error (s.e.) 35) and 784 Euros (s.e. 46) at 49 and 50 years, respectively. For women the difference is even larger but not significant.

\footnotetext{
${ }^{26}$ Similar evidence comes from comparing outcomes at any other pre-programme month conditioning on being at work

${ }^{27}$ This evidence should be taken with caution due to the small sample sizes of these sub-groups, especially on the right tail of the distribution.
} 
Figure 10: Employment rate three years before enrolment in the LM conditional on being at work three years after enrolment, by age, by entitlement to monetary benefits and by gender (LLR estimates and 95\% confidence intervals)
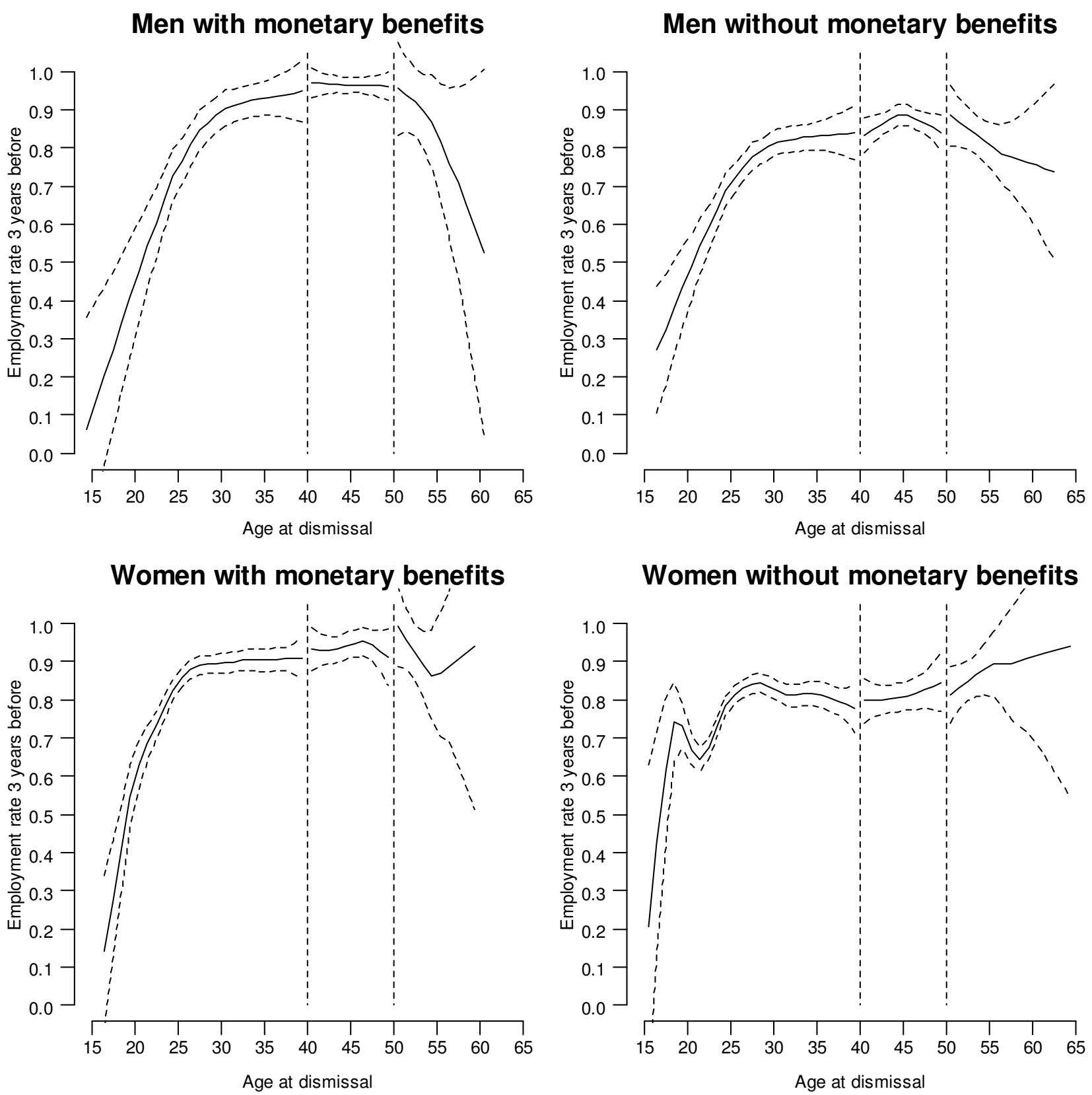
Figure 11: Average gross weakly wage (1,000 Euros 2003) three years before enrolment in the LM conditional on being at work three years after, by age, by entitlement to monetary benefits and by gender (LLR estimates and 95\% confidence intervals)
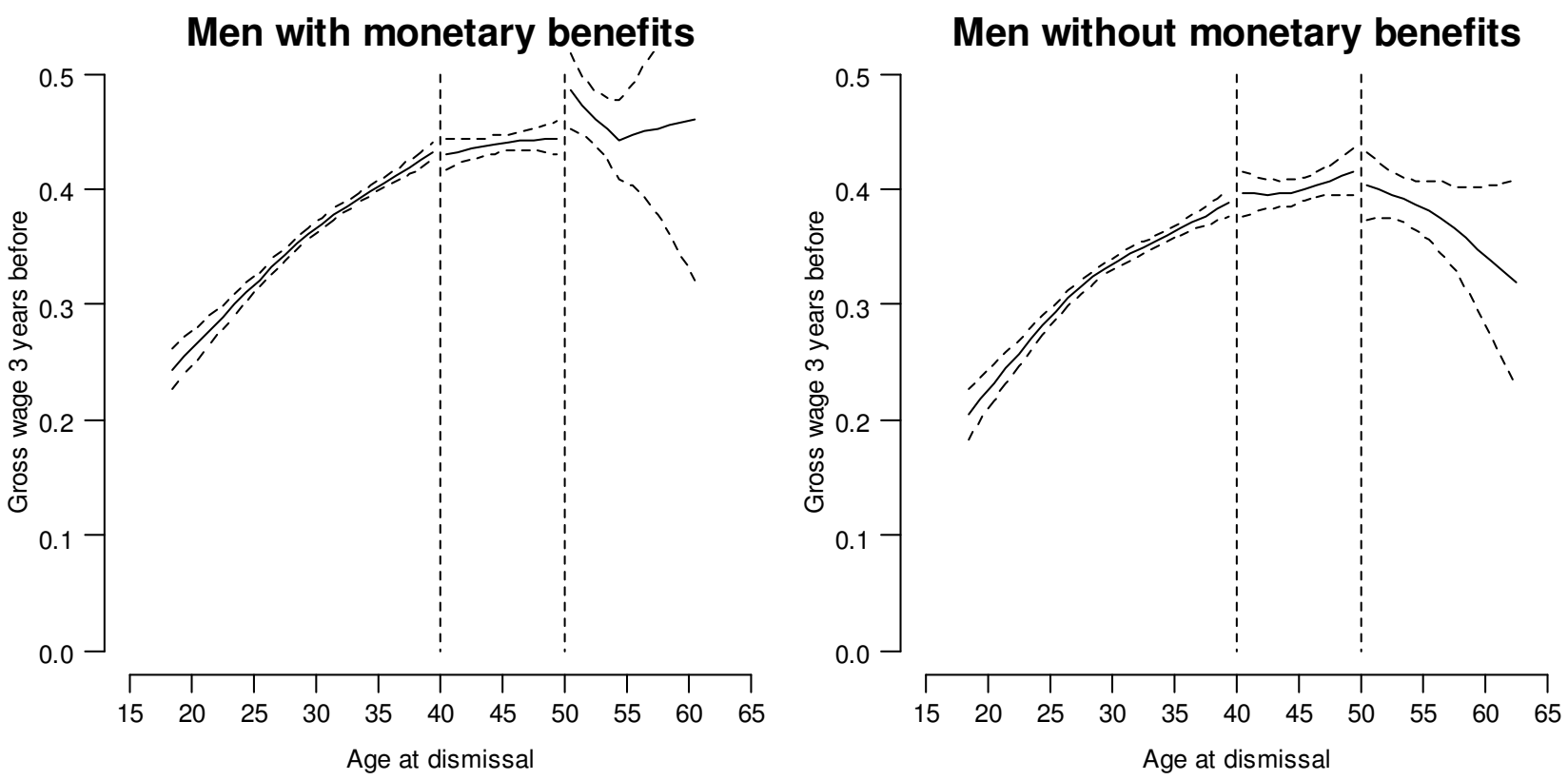

Women with monetary benefits

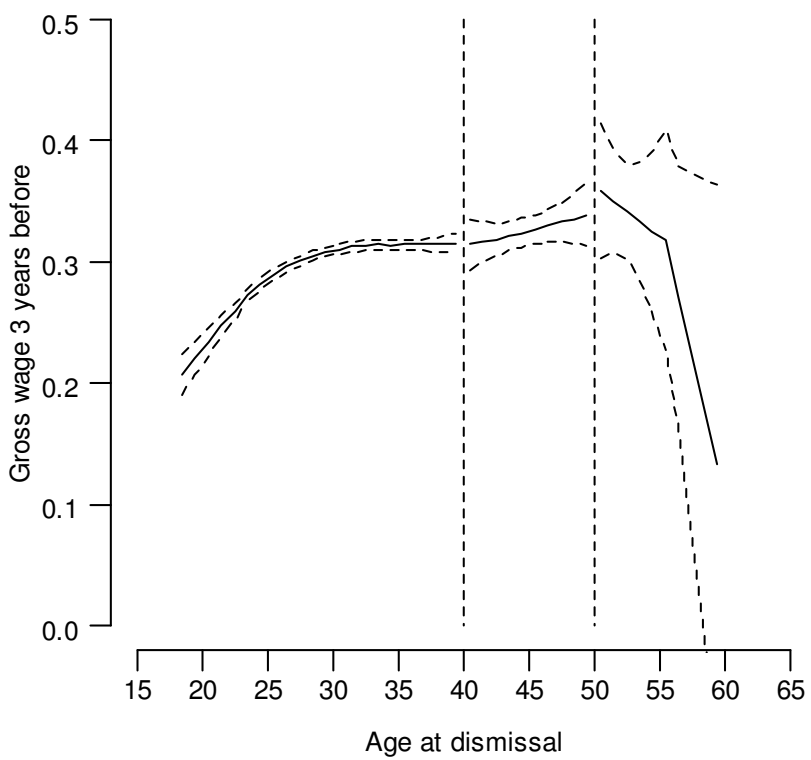

Women without monetary benefits

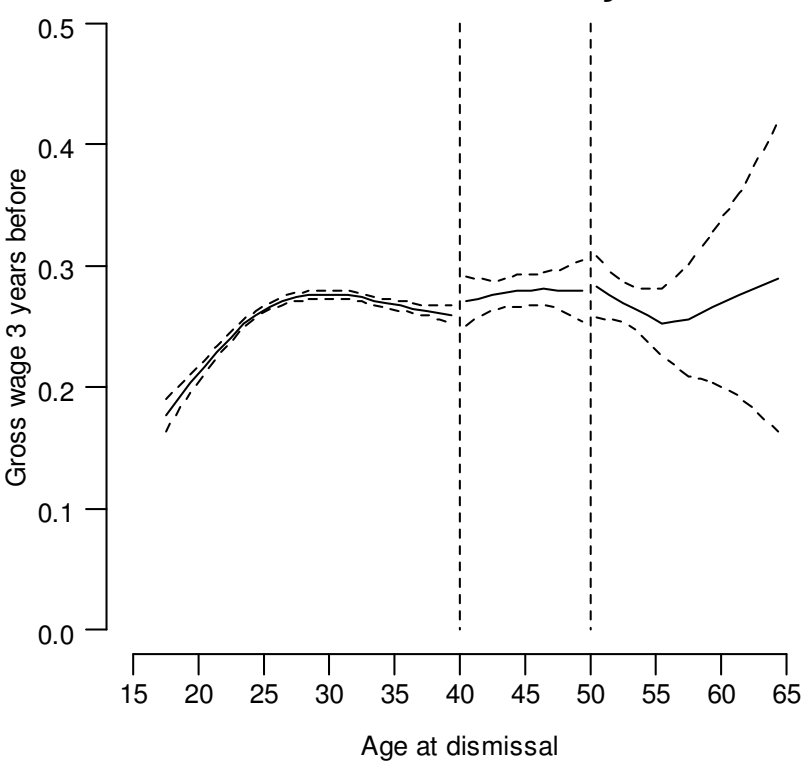


Figure 12: Average gross weekly wage (1,000 Euros 2003) three years after enrolment in the LM, by age, by entitlement to monetary benefits and by gender (LLR estimates and $95 \%$ confidence intervals)
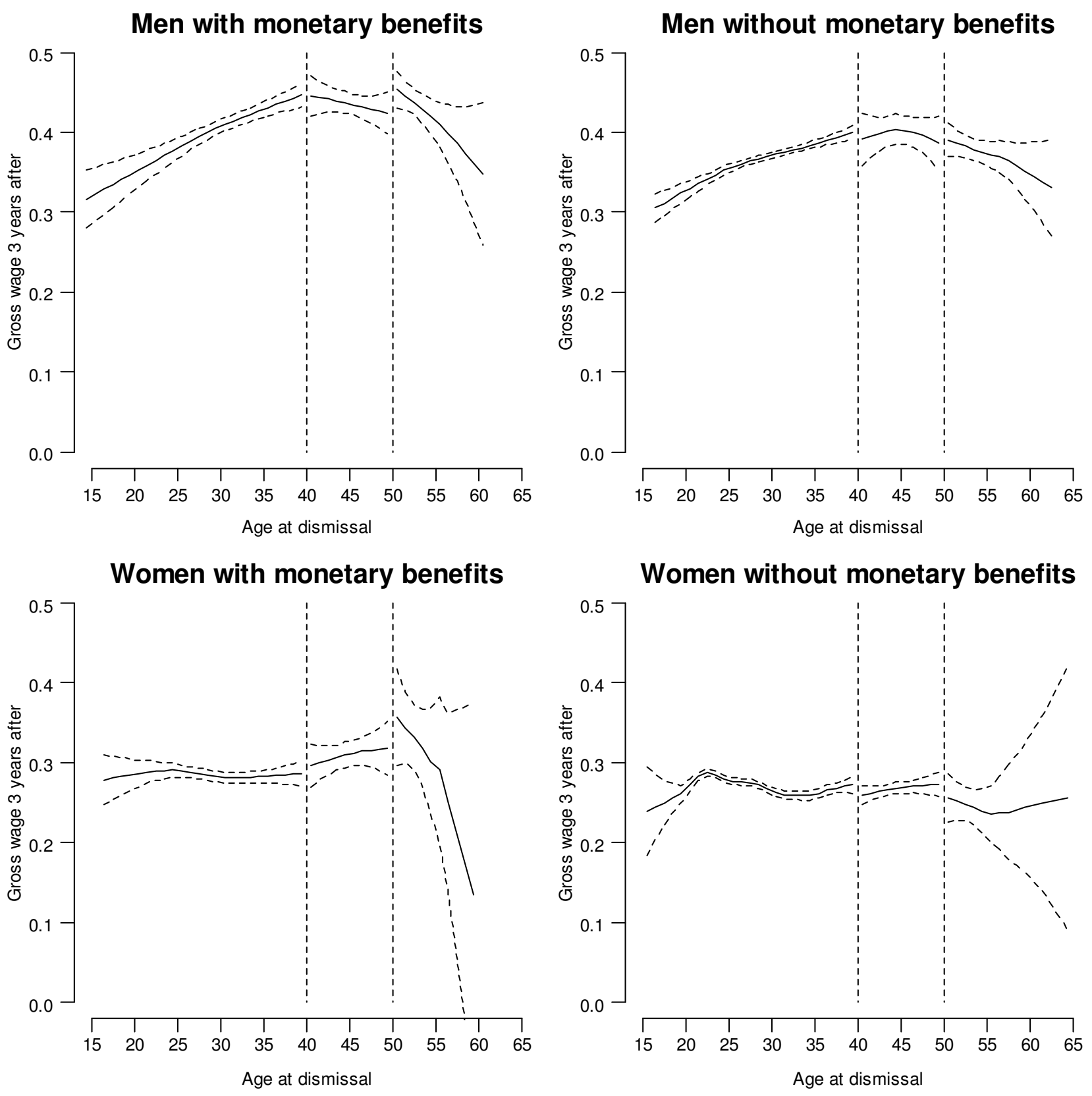
Overall, we do not deem this discontinuity at the $9^{\text {th }}$ decile can be interpreted as a causal effect of the eligibility regime on wages. Rather, we propose to interpret it as a causal effect of the eligibility regime on the composition of the pool of 50-year old enrolled in the LM at work after three years. As we showed (see Figures 7 and 9), most of the persons aged 50 or more enrolled in the LM and entitled to monetary benefits are not at work three years after enrolment, as a result of the option available to them to use the programme as a bridge to retirement. Those who chose to reenter at work - approximately $20 \%$ of the pool both for men and women - are from the upper tail of the wage distribution, i.e. workers who would have been penalised the most by the rule setting a ceiling on the amount of monetary benefit they would have received, had they chosen the "long mobility" option. This is consistent with the evidence from Figure 11, which documents that the pre-enrolment average wage of persons just 50-year old enrolled in the LM and at work three years after enrolment is larger than the corresponding average wage of those just younger than $50^{28}$.

Finally, women with monetary benefits at the 40-year threshold show a peculiar time pattern also for their distribution of wages. As we have seen, women just above the threshold re-enter at work more slowly than their younger colleagues as a causal effect of the longer eligibility they are entitled to. On the other hand, we didn't find any causal effect on average wages. Figure 14, bottom right panel, confirms the latter evidence with reference to the whole wage distribution: no statistically significant difference emerges at the 40-year threshold for the quantiles of the wage distribution three years after enrolment. On the other hand, by the end of the second year, that is when there is a significant causal effect on the re-employment rate, there is also a statistically significant difference at the first decile of the wage distribution: it is 137 Euros (s.e. 11) just below 40, while it is 218 Euros (s.e. 13) just over 40. The difference declines to 46 Euros, still significant, at the first quartile, the estimates being 213 (s.e. 8) and 259 Euros (s.e. 5), respectively. Our conclusion is that women with monetary benefits just over 40 (i.e. holding a two-year eligibility) who choose to delay their re-employment are mainly from the left tail of the wage distribution. These women make the most of the passive component of the programme, spending all the time they are allotted to in the Lists and re-entering at work only when monetary benefits expire. However, by the end of the third year both the re-employment rate and the wage distribution are the same across the 40-year threshold.

\section{Summary and concluding remarks}

In this paper we have estimated the average causal effect of extending by one year the eligibility to the provisions of the Liste di mobilità (LM), an Italian labour market programme targeted to dismissed employees. The empirical analysis has been carried out on the population of workers of the Veneto region - North-East of Italy, who entered the programme in the years 19951998. For such analysis we took advantage of a new linked administrative panel data set. To identify the causal effect we exploit the deterministic dependence of the duration of eligibility on the worker age at dismissal set by the LM rules. We validate the resulting RDD by a number of overidentification tests based on Lee (2008).

Actually, the LM programme is made up of two separate sub-programmes, addressed to two non-overlapping sub-populations of workers, but sharing the rule which assigns the duration of eligibility: it is one year for workers up to 39-year old at the time of dismissal, two years in the 4049 age group, three years for workers aged 50 or more.

\footnotetext{
${ }^{28}$ This is confirmed by looking at the whole distribution of pre-enrolment wages for those at work three years after enrolment, here not reported for sake of brevity. It shows a significant discontinuity only at the $9^{\text {th }}$ decile, similarly to what observed in Figure 13 for wages after enrolment.
} 
Figure 13: Estimated quantiles of gross weekly wage (1,000 Euros 2003) three years after enrolment in the LM by age, by entitlement to monetary benefits and by gender (LLR estimates)
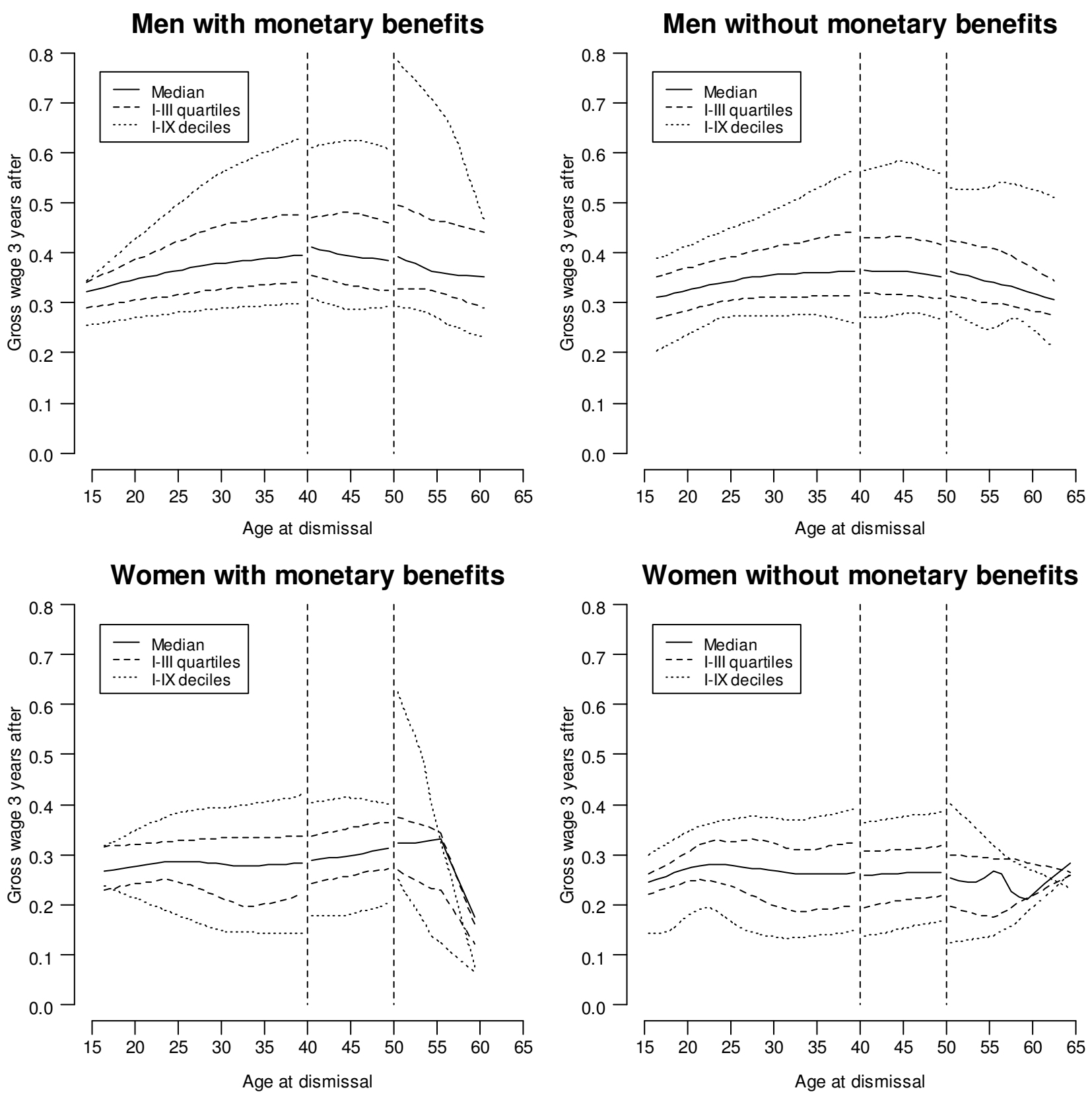
Figure 14: Estimated quantiles of gross weekly wage (1,000 Euros 2003) for women with monetary benefits by age, at various years before and after enrolment in the LM (LLR estimates)

Women working 3 years before

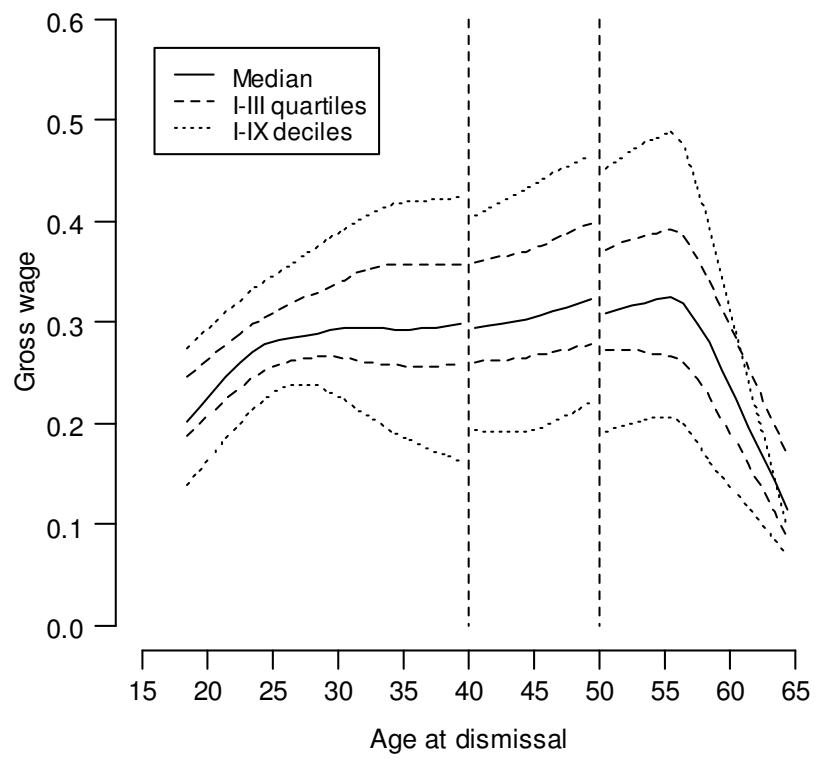

Women working 2 years after

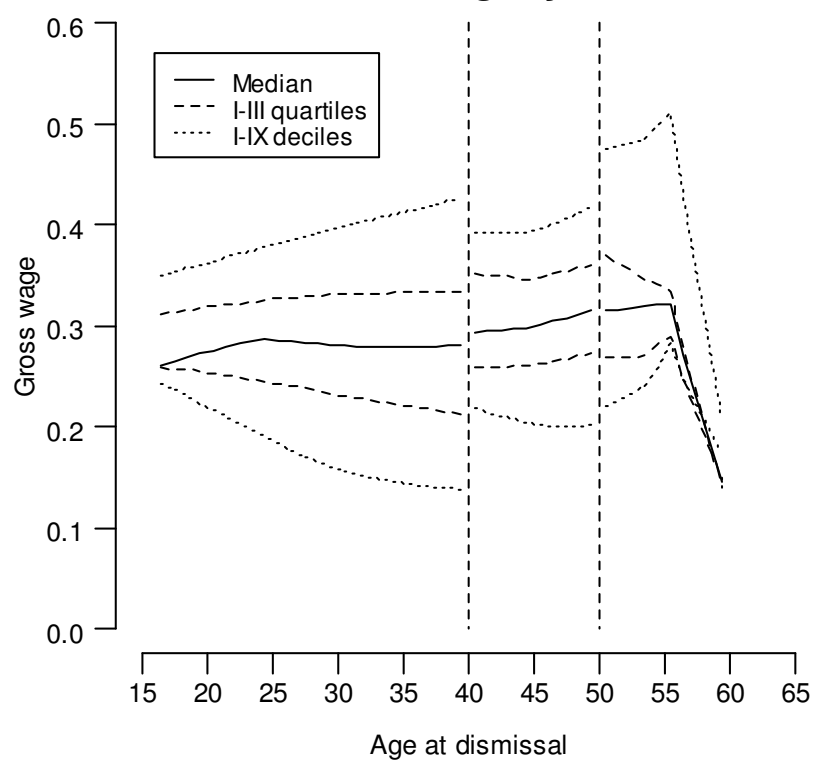

Women working 1 year after

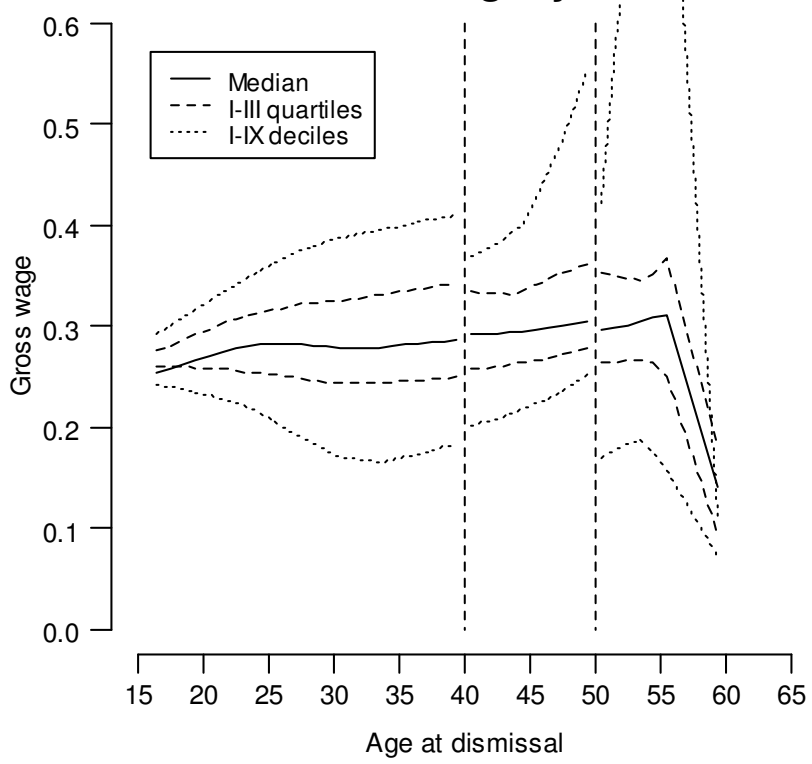

Women working 3 years after

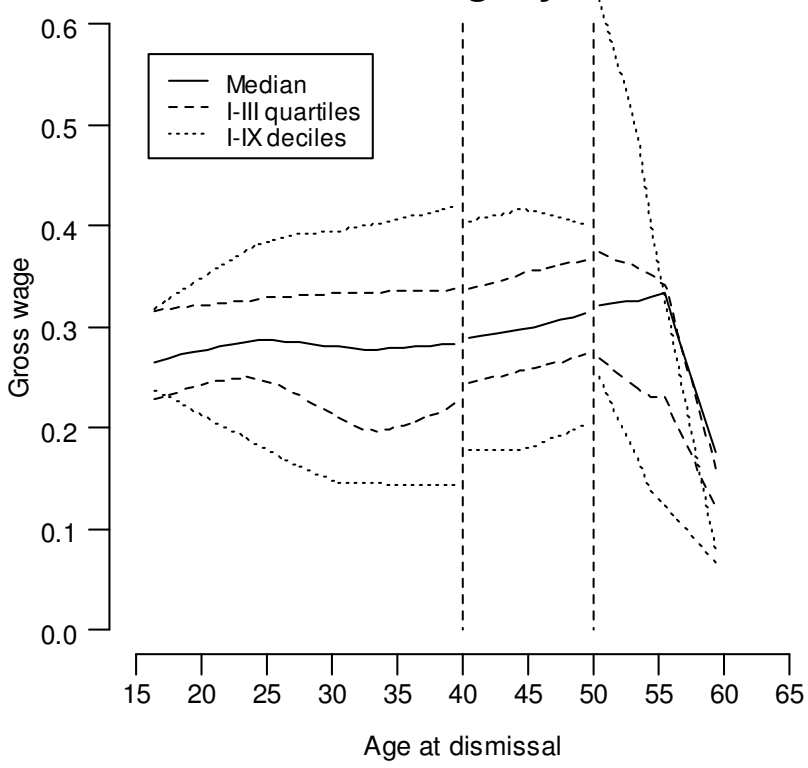


A first sub-programme applies to workers collectively or even individually dismissed by small firms, with less than 15 employees, and its provision consists of a massive rebate on SSCs to any firm recruiting a worker from the LM. The evidence we got is that there is no effect of extending by one year the duration of eligibility both on re-employment probability and on wages during the 36 months subsequent to enrolment in the LM, both at the 40-year and 50-year thresholds.

The second, more elaborate sub-programme applies to workers collectively dismissed by firms with more than 15 employees. It adds to the active component of the previous sub-programme a passive one, consisting of a generous monetary benefit to enrolled workers, which declines moderately with time spent in the LM. The amount of monetary benefit not received yet at the time a LM worker gets a new permanent job is partly transferred to the firm hiring him/her, this way enhancing further his/her probability to receive a job offer. Most importantly, a special provision the so-called "long mobility" - holds for workers aged 50 years or more, who under mild conditions may use the LM as a bridge to retirement.

Results for the second sub-programme are fairly different at the 40- and 50-year threshold, respectively.

At the 40-year threshold there is no significant effect of extending eligibility by one year on re-employment probabilities three years after enrolment. Besides, we find no effect of the additional year of eligibility on wages. This evidence contrasts with most previous studies on the LM, which found a negative effect of the additional year of eligibility on the transition to a new job. Presumably, this is due to the fact that the data set we used is much richer on the labour market history of LM workers - it registers also spells of temporary work, and to the high internal validity of RDD.

The only significant effect at the 40-year threshold is a lower re-employment rate for women aged 40, chiefly those with low wages, by the end of the second year after enrolment. As after three years the effect vanishes, this evidence suggests that low wage women are more responsive to monetary benefits and use them at their best - women aged 39 for one year and women aged 40 for two years, possibly because around their forties they also face family commitments, first of all young children care.

The policy implication we derive from this evidence is that the more generous provision for older workers is of no help in getting them back to work. It just makes the programme more expensive $^{29}$.

Moving to the 50-year threshold, there is a definitely strong causal effect. Slightly more than $20 \%$ of workers aged 50 are back to work three years after enrolling in the LM, while for workers in enrolled the Lists just below their 50s the corresponding rates are approximately $50 \%$ for women and $60 \%$ for men. Which we interpret as the causal effect of the additional provision allowing workers older than 50 to use LM as a bridge to retirement. The provision of the "long mobility" does have perverse effects on these workers, as it operates as an incentive to early retirement. This is in patent contrast with the concern of the European Union (EU) for increasing the employment rate of older workers, a concern particularly relevant for Italy which lags well behind the EU average in this respect.

\footnotetext{
${ }^{29}$ To quantify the additional costs induced by the more generous provisions for workers aged 40 is problematic, mainly because of the role of temporary contracts, which extend the eligibility duration. However, from a careful consideration of these provisions, and from the illustrative example presented in Section 2.3, it is reasonable to presume that the main part of the additional costs consists of the higher benefit transfer for older workers.
} 
Finally, it is worth noting that, if order to characterise the LM as a welfare to work programme, the implementation of "activation" provisions, monitoring of job-seekers and enforcement of work tests comes out crucial.

\section{References}

Anastasia B. et al. (2004), Interazione fra sussidi passivi e incentivi al reimpiego: provenienze ed esiti di lavoratori iscritti nelle Liste di Mobilità. Rapporto finale, Venezia: Agenzia Veneto Lavoro (mimeo).

Atkinson A.B. and J. Micklewright (1991), "Unemployment compensation and labor market transitions: A critical review", Journal of Economic Literature, 29: 1679-1727.

Blank R.M. (2002), "Evaluating welfare reform in the United States", Journal of Economic Literature, 40: 1105-1066.

Brunello G. and R. Miniaci (1997), "Benefit transfers in Italy: An empirical study of mobility lists in the Milan area", Oxford Bulletin of Economics and Statistics, 59: 329-347.

Caruso E. and G. Pisauro (2005), "Licenziamenti definitivi o temporanei? Durata della disoccupazione nelle Liste di mobilità tra nuovi e vecchi datori di lavoro", Politica Economica, 21: 361-399.

Cleveland W.S. (1979), "Robust locally weighted regression and smoothing scatterplots", Journal of the American Statistical Association, 74: 829-836.

Cleveland W.S. and E. Grosse (1991), “Computational methods for local regression”, Statistics and Computing, 1: 47-62.

Del Conte M., C. Devillanova and S. Morelli. (2004), "L'indice OECD di rigidità nel mercato del lavoro: una nota", Politica Economica, 20: 335-356.

Esping-Andersen G. (1990), The three worlds of the welfare capitalism, Cambridge: Polity Press.

Fan J. and I. Gijbels (1996), Local polynomial modelling and its applications,. London: Chapman and Hall.

Fredriksson, P. and M. Söderström (2008), Do unemployment benefits increase unemployment? New evidence on an old question, IZA Discussion Paper No. 3570, Bonn: IZA.

Grogger J.T. and L.A. Karoly (2005), Welfare reform: Effects of a decade of change, Cambridge, MA: Harvard University Press.

Hahn J., P. Todd and W. Van der Klaauw (2001), "Identification and estimation of treatment effects with a regression-discontinuity design”, Econometrica, 69: 201-209.

Ham, J. and R. Lalonde (1996), “The effect of sample selection and initial conditions in duration models: Evidence from experimental data on training", Econometrica, 64: 175-205.

Heckman J.J. and B. Singer (1984), "A method for minimising the impact of distributional assumptions in econometric models for duration data", Econometrica, 52: 271-320.

Hurvich C.M. and J.S. Simonoff (1998), "Smoothing parameter selection in nonparametric regression using an improved Akaike information criterion", Journal of the Royal Statistical Society B, 60: $271-293$.

Ichino P. (2004), "Job security and the value of equality. A tentative law \& economics approach to the problem of effectiveness of the workers' protection against dismissal for economic reasons", paper presented at the University of Vienna, January 31, 2004 (mimeo). 
Imbens G. and T. Lemieux (2008), "Regression discontinuity designs: A guide to practice", Journal of Econometrics, 142, 2: 615-635.

Kluve J. et al. (2007), Active labor market policies in Europe: Performance and perspectives, Berlin-Heidelberg, Springer.

Lee D.S. (2008), "Randomized experiments from non-random selection in U.S. House elections", Journal of Econometrics, 142, 2: 675-697.

Martin J.P. and D. Grubb (2001), "What works and for whom: A review of OECD countries' experience with active labour market policies", Swedish Economic Policy Review, 8: 9-56.

Martini A. and L. Mo Costabella (2007), "Una valutazione degli effetti indesiderati dell'istituto della mobilità su imprese e lavoratori", Politica Economica, 23 (3): 259-288.

Meyer B.D. (1990), “Unemployment insurance and unemployment spells”, Econometrica, 58: 757 782.

Meyer B.D. (1995), "Lessons from the U.S. unemployment insurance experiments", Journal of Economic Literature, 33: 91 -131.

Mortensen D. and C. Pissarides (1999), "New developments in models of search in the labor market ", in O.C. Ashenfelter and D. Card (eds.), Handbook of Labor Economics, Vol. 3C, Amsterdam: Elsevier.

OECD (2004), OECD Employment Outlook 2004, Paris: OECD Publishing.

OECD (2005), OECD Employment Outlook 2005, Paris: OECD Publishing.

Paggiaro A., E. Rettore and U. Trivellato (2005), The impact of the Italian 'Mobility Lists' on employment chances: New evidence from linked administrative archives, Progetto MIUR 'Metodi e studi di valutazione degli effetti di politiche del lavoro, di aiuto alle imprese e di welfare', Working Paper No. 65, Padova: Dipartimento di Scienze Statistiche, Università di Padova.

Paggiaro A. and U. Trivellato (2002), “Assessing the effects of the 'Mobility Lists' programme by flexible duration models", Labour, 16: 235-266.

Schivardi F. and R. Torrini (2004), Firm size distribution and employment protection legislation in Italy, «Temi di discussione» n. 504, Roma: Banca d'Italia.

Snower D. (1994), "Converting unemployment benefits into employment subsidies", American Economic Review, 84 (2): 65-70. 